\title{
Cross-Dialectal Novel Word Learning and Borrowing
}

\author{
Junru Wu ${ }^{1,2 *}$, Wei Zheng ${ }^{1}$, Mengru Han ${ }^{1}$ and Niels O. Schiller ${ }^{2,3}$ \\ ${ }^{1}$ Laboratory of Language Cognition and Evolution, Department of Chinese Language and Literature, East China Normal \\ University, Shanghai, China, ${ }^{2}$ Leiden University Centre for Linguistics, Leiden, Netherlands, ${ }^{3}$ Leiden Institute for Brain and \\ Cognition, Leiden, Netherlands
}

OPEN ACCESS

Edited by:

Xiaolin Zhou,

Peking University, China

Reviewed by:

Xiaoqing $\mathrm{Li}$,

Peking University, China

Hassan Mohebbi,

European Knowledge Development Institute (EUROKD), Turkey

${ }^{*}$ Correspondence: Junru Wu

jrwu@zhwx.ecnu.edu.cn

Specialty section: This article was submitted to

Language Sciences,

a section of the journal

Frontiers in Psychology

Received: 01 July 2021 Accepted: 26 August 2021 Published: 30 September 2021

Citation:

Wu J, Zheng W, Han M and Schiller NO (2021) Cross-Dialectal Novel Word Learning and Borrowing.

Front. Psychol. 12:734527.

doi: $10.3389 /$ fpsyg.2021.734527
The objective of this paper was to study the cognitive processes underlying cross-dialectal novel word borrowing and loanword establishment in a Standard-Chinese-to-Shanghainese (SC-SH) auditory lexical learning and borrowing experiment. To investigate these underlying cognitive processes, SC-SH bi-dialectals were compared with SC monolectals as well as bi-dialectals of SC and other Chinese dialects (OD) to investigate the influence of short-term and long-term linguistic experience. Both comprehension and production borrowings were tested. This study found that early and proficient bi-dialectism, even if it is not directly related to the recipient dialect of lexical borrowing, has a protective effect on the ability of crossdialectal lexical borrowing in early adulthood. Bi-dialectals tend to add separate lexical representations for incidentally encountered dialectal variants, while monolectals tend to assimilate dialectal variants to standard forms. Bi-dialectals, but not monolectals, use etymologically related morphemes between the source and recipient dialects to create nonce-borrowing compounds. Dialectal variability facilitates lexical borrowing via enriching instead of increasing the short-term lexical experience of learners. The long-term bi-dialectal experience of individuals, as well as their short-term exposure to each specific loanword, may collectively shape the route of lexical evolution of co-evolving linguistic varieties.

Keywords: dialect, lexical borrowing, word learning, lexical processing, bilingualism

\section{INTRODUCTION}

Few languages in the world come with no loanwords. Loanwords are very common if lexical borrowing across co-evolving dialects is taken into consideration. Lexical borrowing across dialects prevails with practical significance. For instance, new words, e.g., computer in the 1980s, since they are introduced to a new linguistic community, usually primarily enter the more prestigious dialect and then spread from such a dialect (the source dialect) to other dialects (the recipient dialects). This ongoing historical process deeply shapes the current appearance of co-evolving dialects, as well as co-evolving languages.

Borrowing is a term usually used in classic linguistic studies of language evolution. However, language evolution receives profound collective influences from individual behaviors (Trudgill, 1986; Fitch, 2007). Specifically, lexical borrowing is realized through the cross-linguistic behaviors 
of bilinguals and monolinguals, which is known as a common way that individuals modify their speech (accommodate lexical forms) in order to match those of their interlocuter (Giles et al., 1973; Trudgill, 1986) ${ }^{1}$.

Since the collective behaviors of individuals are considered for the historical course of lexical borrowing, it is reasonable to assume that the way borrowing takes place is influenced by the cognitive costs it charges from individuals. Regarding what makes it difficult to borrow words, numerous linguistic debates have arisen in the past few centuries, e.g., on the existence of substratum interference in the linguistic society (as reviewed by Thomason and Kaufman, 1991) and on lexical features (as reviewed by Wang and Wang, 2004). However, it remains unclear in many aspects how this borrowing is related to the cognitive processing of words and influenced by the experiences of individuals.

For instance, bi-dialectals are the group that most frequently is involved in lexical borrowing while interdialectal lexical borrowing gives rise to interdialectal forms, as noted in the study by Trudgill (1986), which deeply shapes the results of dialectal co-evolution. However, little is known about when and why bi-dialectals would find a source form difficult to borrow. Therefore, the current research offered a psycholinguistic approach to understand this problem.

To our knowledge, although some recent studies had investigated interdialectal lexical adaptation, e.g., Swerts et al. (2021), very few experimental studies had directly tapped into the issue of lexical borrowing in the context of bi-dialectism. Hence, before moving on to the psycholinguistic backgrounds of the current research, we introduced one sociolinguistic study which has critically discussed individual behaviors in lexical borrowing.

\section{From Nonce Borrowing to Established Loanwords}

Typical "loanwords" are widely accepted as words that recur relatively frequently. These words are widely used and have achieved a certain level of acceptance in the recipient linguistic community (Mackey, 1970; Poplack and Sankoff, 1984). These features distinguish established borrowing from single-word code-switching. However, the research of Poplack et al. (1988) studied Canadian English-French/French-English bilinguals from highly bilingual communities and have proven the existence of nonce borrowing, known as loans which are adapted from source-language words and used incidentally in recipient languages. These borrowings have two important features. First, they are incidental and realized with inconsistent pronunciations, in contrast to established borrowings, which usually have established loan forms. Second, they usually involve phonological and morphological adaptation, in contrast to single-word code-switching, which maintains the source forms in the recipient context.

\footnotetext{
${ }^{1}$ Alternatively, individuals of a linguistic society can (a) learn foreign words for old concepts that have existing native words, or (b) create new native forms for new concepts without reference to foreign forms (based on Haugen, 1950 and Weinreich, 1953; as reviewed by Grzega, 2003). However, these two types would not influence the source language as much as lexical borrowing.
}

Although most nonce loanwords are short-lived, we presumed that nonce borrowing in language evolution may be the predecessor of established borrowing. One type of supportive evidence may be the one-to-many mapping in the early stages of lexical borrowing which has been documented in the literature. For instance, the Sanskrit word "Buddha" yielded at least four Chinese phonological loan forms between 220 and 589AC (Ji,

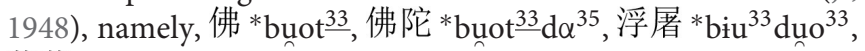
菩萨 ${ }^{*}$ buo $^{33} \mathrm{~s} \alpha t^{3}$. If we had taken into consideration all the documented pronunciations of these characters in Middle Chinese rime books, the same Sanskrit source word "Buddha"" would be associated with even more Chinese loan pronunciations in that historical period, when Sanskrit words were introduced by bilingual monks into Chinese in large quantities with the spread of Buddhism. Similar lexical variation was reported in the study by Poplack et al. (1988) for contemporary nonceborrowing in the French-English bilingual society, only that most of those nonce loan forms as documented did not get established in that linguistic society. Similarly, studies tracking the history of modern loan words have also shown a pattern that, at the start of a language contact case, with the introduction of new concepts, many candidates of loan forms come to existence, frequently with competing lexical forms associated with the same source forms. However, after the beginning stage of contact, usually only one or two loan forms are kept for each loanword in the linguistic community. For instance, until 2009, 56\% of Shanghainese (SH) loan forms of foreign origin that had been documented in 1945 have been replaced and many of the remained have taken altered pronunciations or written with different Chinese characters (You, 2016). However, psycholinguistic mechanisms involved in individuals who made the collective unconscious decision in loan form establishment are still worth investigating.

When loanwords are getting established, the collective influence from individuals probably starts taking effect when individuals first hear and/or produce the loan forms with meaning. Hence, studying the cognitive processes involved in the establishment of nonce loanwords may provide a new perspective that helps one to understand the cognitive mechanism involved in the co-evolution of closely related language varieties.

To study this collective individual course of loan establishment, the current experimental study operationalized the research question by comparing new nonce loanwords and incidentally established loanwords in lexical recognition and production.

Specifically, source novel words were created by combining novel meanings with novel forms in the source language to exclude the influence of previous lexico-specific knowledge. Then, recipient nonce loanwords were created for these source words. To control for the way and extent the loanwords differ

\footnotetext{
${ }^{2}$ Here we refer to http://ccdc.fudan.edu.cn/linguae/ltcPhonology.jsp and use Wuyun Pan(潘 悟 云)'s reconstructions of Middle Chinese pronunciation. Some Chinese characters have multiple phonological status in the Middle Chinese rime dictionaries Guangyun 广韵 and Jiyun集韵. Here we use the phonological status 並母一等合口呼没韵 for the reconstruction of “佛”,並母非重纽三等开口呼尤韵 for “浮”, and 並母一等合口模韵平声(Guangyun only) for “菩”.
} 
from the source words, these loanwords were all designed with morphological and phonological adaptations.

1. After the participants acquired the source novel words with meaning, some of the corresponding loanwords are auditorily presented to the participants for them to figure out the meaning. In this process, the participants need to transfer their previous and recently acquired lexical knowledge, i.e., about the source novel word, to recognize the novel loans. This is the comprehension borrowing of novel nonce loanwords, which mimics the very beginning of loan receiving in a linguistic community. However, note that comprehension borrowing may be more possible between dialects because dialects have a relatively high degree of mutual intelligibility (for example, see Wang and Van Heuven, 2015 for an investigation on the mutual intelligibility across Chinese dialects), while between remote languages there would be only the semantic and phonological similarities of the source and recipient forms to rely on.

2. Having experienced such auditory exposure to these loans, the participants had briefly established the lexical representations of these loans in their memory. Therefore, these loans had become incidentally established loanwords. When these participants were asked to name images (which represent the lexical meaning) with the incidentally established loanwords, this is the production borrowing of incidentallyestablished loanwords, which mimics the first usage of bidialectal individuals of a newly acquired loanword in the bidialectal community.

3. We prepared other novel loanwords that were not presented to the participants in the comprehension borrowing test, and the participants only learned the corresponding source forms with meaning. Afterwards, these novel loanwords remained secret in the recipient dialect. However, the participants were still asked to name the images corresponding to these loanwords in the recipient dialect. In this way, they had no other option but to create these nonce loanwords by themselves. To achieve this goal, they needed to actively transfer their lexicalspecific knowledge from the source dialect, as well as their previous knowledge on the phonological and morphological relations between the two dialects (if available). This is the production borrowing of nonce loanwords, which mimics the first creative usage of bi-dialectal individuals of nonce loanwords in their bi-dialectal community (lexical creation; Weinreich, 1953).

By comparing the production borrowing of nonce loanwords and that of incidentally established loanwords, we could tap into the cognitive processes involved in the very beginning of loanword establishment. Also, we could study the cognitive process underlying the comprehension and production of nonce loanwords.

Nonce borrowing appears more frequently in highly bilingual linguistic communities (Poplack et al., 1988), which suggests that the cognitive processes involved may be influenced by community members' long-term bilingual experience. Hence, we further investigated how socio-linguistic background may influence the cognitive performance of individuals in the establishment of loanwords. This is related to previous cognitive findings on word learning
TABLE 1 | Different types of long-term linguistic experience (header column) and their predicted influences on the effects of dialectal backgrounds (header row).

\begin{tabular}{llll} 
& \multicolumn{2}{c}{ Dial. background } & \\
\hline $\begin{array}{l}\text { Long-term ling. } \\
\text { Experience }\end{array}$ & $\begin{array}{l}\text { SC } \\
\text { monolectals }\end{array}$ & $\begin{array}{l}\text { SC-OD } \\
\text { bi-dialectals }\end{array}$ & $\begin{array}{l}\text { SC-SH } \\
\text { bi-dialectals }\end{array}$ \\
\hline $\begin{array}{l}\text { Long-term bi-dialectal } \\
\text { exposure }\end{array}$ & No & Yes & Yes \\
$\begin{array}{l}\text { Long-term recipient- } \\
\text { dialect-specific } \\
\text { experience }\end{array}$ & No & No & Yes \\
$\begin{array}{l}\text { Lexical semantic } \\
\text { experience to } \\
\text { morphemes }\end{array}$ & Yes & Yes & Yes \\
\hline
\end{tabular}

and bilingual lexical processing, which are reviewed as follows.

\section{Age Effects in Novel Word Learning and Mental Establishment of Loanwords}

Word learning is influenced by many factors, of which the factor age was the focus of the current research on lexical borrowing. While many studies have shown age-related deterioration of phonological and syntactic learning abilities (Lenneberg et al., 1967; Werker and Hensch, 2015; Reh et al., 2021), contradicting findings in studies on the vocabulary development of deaf individuals have triggered a long-lasting debate about the existence of the sensitive period for word learning (Newport et al., 2001; Lederberg and Spencer, 2005; Connor et al., 2006).

The influence of age on word learning becomes more complicated when bilingualism is taken into consideration. On the one hand, the early age of L2 acquisition may create a more integrated bilingual mental lexicon (Sabourin et al., 2014; Cardimona et al., 2016). On the other hand, although nondialectal bilinguals as compared with monolinguals usually show lexical disadvantages (as reviewed by Bialystok, 2009), such a disadvantage is largely absent by early and proficient bi-dialectals (Wu, 2015, pp. 143-188; Wu et al., 2019), who are special in the sense that they are highly experienced with cross-dialectal lexical learning and lexical borrowing. Therefore, it is reasonable to ask whether bi-dialectal exposures would delay the deterioration of word-learning ability.

Naturally, this question is raised under the presumption that there is an age-related deterioration of word-learning ability by monolectals, which was verified in the current research. Then, if it was found that bi-dialectals maintain better wordlearning abilities until a later age, a follow-up question would be whether this advantage can further benefit their lexical borrowing. In order to focus on the influence and interaction of bi-dialectism and age, this study controlled all the other known predictors for word learning (Kaczer et al., 2018), including the availability of semantic information (for examples, see Gaskell and Dumay, 2003; Qiao and Forster, 2013; Li and Xu, 2021), referential familiarity (Barcroft and Sunderman, 2008; Kaushanskaya et al., 2013), contexts (e.g., Mestres-Missé et al., 2008; Lindsay and Gaskell, 2013), semantic clustering (e.g., 
Tinkham, 1997; Finkbeiner and Nicol, 2003; Erten and Tekin, 2008), form variability (Lively et al., 1993; Keuleers et al., 2007; Kriengwatana et al., 2014), and tasks (for e.g., see Forster, 1985; Jiang and Forster, 2001; Witzel and Forster, 2012; Qiao and Forster, 2017). Within all the known semantic predictors for word learning, merely one factor was considered in this research, namely the semantic concreteness of morphemes that form the novel words. This semantic factor was considered because it covaries with a morphological probability of the morphemes in the recipient dialect (see a further explanation later).

\section{Bi-Dialectal Particularities in Cross-Dialectal Lexical Borrowing}

One aim of the current study was to test for potential cognitive particularities of bi-dialectals in interdialectal lexical borrowing. Thus, we compared bi-dialectals against monolectals of comparable linguistic backgrounds.

As few studies directly compared bi-dialectals and monolectals in lexical processing, here we primarily introduced known cognitive differences on the cross-linguistic lexical processing between bilinguals and monolinguals. Early and proficient bilinguals (Antoniou et al., 2012; Wu et al., 2017; De Leeuw and Celata, 2019; Wig and García-Sierra, 2021) seem to be more adaptive than monolinguals (for e.g., see Best and Strange, 1992, Perceptual Assimilation Model, PAM) in speech perception. Also, compared with L2 learners, early and proficient bilinguals are more likely to maintain separate instead of joined lexical representations for etymologically-related translation equivalents (ETEs), i.e., word pairs/sets that have common origins, refer to the same concepts, and are similar in sound, which is either cognates inherited from a common ancestor language or loans borrowed across languages. These ETEs are cognitively processed differently as compared with language-specific words (e.g., Sumner and Samuel, 2009; Dijkstra et al., 2010; Mulder et al., 2015; Larraza and Best, 2018; Wu et al., 2019).

Hence, we hypothesized that when carrying out cross-dialectal lexical borrowing, early and proficient bi-dialectals might be biased toward adopting the adaptive perceptual mechanisms and create separate lexical representations across dialects, while monolectals might be biased toward perceptual assimilation and joined lexical representations. This claim probably also applies to production borrowing, considering the studies of Poplack et al. (1988) and Ernestus and Baayen (2003) as mentioned above.

Interestingly related to these findings, previous phonological studies on lexical borrowing have also distinguished phonological and phonetic adaptions (for e.g., see Kang, 2010) as well as adaption vs. direct surface adoption (Aktürk-Drake, 2014). These studies also suggested that choices during loan adaptation may be modulated by both perceptual factors and the familiarity of individuals with the source language, e.g., foreign vs. near-native.

To test for the alternative mechanisms of bi-dialectals and monolectals when it comes to lexical borrowing, the current study adopted similarity-related interference as a probe for the emergence of lexical representation (Marian et al., 2008; Dijkstra et al., 2010; Wu et al., 2019) and used novel
ETE forms of recently learned novel words to control for prior lexical-specific experience. This approach assumed that only separate lexical representations could interfere with each other. Participants who primarily assimilated loan forms to source lexical representations would primarily show similarityrelated facilitation, while participants who created new lexical representations for the loan forms would show interfering or non-linear similarity effects. Also taking into consideration the above-mentioned different biases of monolinguals vs. bilinguals, we expected monolectals to show similarity-based facilitation and bi-dialectals to show interfering or non-linear effects of similarity.

Following the question on the particularities of bi-dialectals, another question requires further investigation, i.e., whether previously observed bilingual lexical effects resulted from the additional lexical experience of bilinguals with specific languages, or contrasts of cognitive features by bilinguals vs. monolinguals, or both.

The current study tapped into this question by exposing monolectals and two groups of bi-dialectals to the same source and recipient dialects. The long-term linguistic experience of bi-dialectals differed in a way that one group of bidialectals (Standard-Chinese-Shanghainese; SC-SH bi-dialectals) were familiar with the recipient dialect (Shanghainese; $\mathrm{SH}$ ) and the other bi-dialectals (Standard-Chinese-Other-Dialect; SC-OD bi-dialectals) were not, as shown in Table 1. We predicted that effects specific to the experience with the recipient-dialect should only be found by the former group, while non-specific bi-dialectal effects should be found by both groups of bi-dialectals. Nonspecific bi-dialectal exposure may change the way bi-dialectals of the other Chinese dialects integrate or create new lexical representations, and bi-dialectals may be able to apply this operational knowledge to unfamiliar dialects. Moreover, if nonspecific long-term bi-dialectism takes effect, we expected to find evidence for the other bi-dialectals in the recipient dialect that they do not speak (i.e., SC-OD bi-dialectals in $\mathrm{SH}$ ) also to create separate lexical representations for source and loan forms.

Hence, this study compared the lexical borrowing processes of bi-dialectals and monolectals and investigated whether the differences originate from different specific experiences to the recipient dialect or from bi-dialectism in general.

\section{Holistic Casting versus Morpheme-Based Re-encoding in Lexical Borrowing}

Another issue to be investigated is holistic casting vs. morpheme-based re-encoding in lexical borrowing. There have been many sociolinguistic and historical discussions regarding the hierarchy of linguistic units under contact. Chinese dialects, as analytic in typology, share many etymologically aligned morphemes, which also form many etymologically aligned compounds, can serve as an ideal test case. Actually, in the contact linguistic literature, as long as Chinese is involved, mono-syllabic morphemes are usually assumed as the primary units of borrowing (for e.g., see Wang and Lien, 1993; Xian, 2012), whereas cross-linguistic borrowing can also involve phonological adaptation of sub-syllabic units 
such as consonant onset, rhymes, and tones (for e.g., see Yang, 1982; Wang and Lien, 1993; Wang, 2005), which can be attributed to word-wise phonological adaptation. Although the effects of word boundaries are less studied in those works, in studied cases, parallel loan forms that can be respectively attributed to morpheme-based and whole-word-based are rather frequent, especially between originally unrelated but co-evolving languages. For instance, in the case of Korean language which has been borrowing Chinese morphemes and words throughout the past two thousand years, the Chinese word 上 海, 'Shanghai' (up + sea), has two parallel loan forms, which are "holistically casted" 상하이, /sang.ha.i/, and "morpheme-based" 상(上)해 (海)/sang.he/ ( $\mathrm{Yu}$ and $\mathrm{Wu}, 2021$ ). So far, little is known about the cognitive base for the emergence of such lexical variance.

In other languages, it is also the case that previous experimental studies have supported both the phonological (for e.g., see Peperkamp et al., 2008; Aktürk-Drake, 2014) and morphological adaptations during nonce borrowing. For instance, the study of Ernestus and Bayen (2003) found that lexical phonotactics of recipient-language morphemes would guide the selection of phonemes in creating nonce loanwords. Hence, both phonological adaptation and morpheme-based lexical creation processes may be involved in the creation of nonce loanwords.

Moreover, cognitive studies on word-learning have also shown that learners shift their attention from separated constituents to the whole words when they learn compound words (Kaczer et al., 2015). These findings inspired the current research to investigate the activation of morphological constituents and the emergence of whole-word representations during lexical borrowing.

Thus, the question lies on whether and when individuals would cast the source form holistically into a new form in the recipient language or re-encode etymologically related morphemes between the two linguistic varieties.

To investigate this question, the current research used novel compounds made of existing morphemes as learning targets and adopted morphological probability as a probe predictor for the activation of constituents. While the morpheme frequencies of the novel compounds in the recipient dialect were manipulated, their morpheme frequencies in the source dialect were controlled. In this way, the morphological probability of the novel compounds in the recipient dialect was implicitly manipulated. For instance, the Chinese morphemes 脖“neck" and 拖 "drag" have similar frequencies in SC as /bo35/ and /thuo55/. However, frequencies of their counterparts differ greatly in SH: the character 脖/bo23/ "neck" is much less frequent than the character 拖/thu55/ "drag" because SH primarily uses another morpheme, /tcin55/, for the concept "neck."

With this manipulation, the appearance of morphologicalprobability effects during lexical borrowing would indicate the activation of morphological constituents in the recipient dialect and hence would imply morpheme-based re-encoding. Specifically, if it was observed that a loan compound that was morphologically less probable in the recipient dialect, e.g., *脖 澡/bo11dzho23/ which contains the SH less frequent脖/bo23/, “neck," triggered significantly larger processing cost than a morphologically-more-probable loan compound, e.g., *拖庙/thu55mis21/ which contains the $\mathrm{SH}$ more frequent拖/thu55/, “drag." This would indicate that morphemes in the recipient dialect are activated. Moreover, considering the above-mentioned potential differences between monolectals and bi-dialectals with respect to lexical-borrowing mechanisms, we predicted that bi-dialectals but not monolectals would be sensitive to morphological probability in the recipient dialect during both comprehension and production borrowing.

Note that the morphological probability of the ETE loanwords in $\mathrm{SH}$ covaries with semantic concreteness of compound constituents. This is because the recipient dialect $\mathrm{SH}$ is a lessprestigious Chinese dialect and less-prestigious dialects tend to borrow more literary words from national standards (standard varieties, a type of "high variety" as termed by Ferguson, 1959) while keeping their own everyday words ${ }^{3}$. Abstract words, e.g., union, are usually more literary than concrete words, e.g., nose, in their meaning (Dixon, 1997). As a result, with the morphological probability of novel words controlled in the source dialect SC, higher morphological probability in SH (a non-standard variety) is related to higher concreteness.

However, the current design could distinguish probability and concreteness effects. Since SC monolectals have no prior knowledge of SH morphological probabilities, it was reasonable to predict that real effects of Shanghainese morphemes were only to be found by SC-SH bi-dialectals, and perhaps also by SCOD bi-dialectals (which would be mediated by the probability of SC-originated morphemes in these non-prestigious Chinese dialects), but not by the SC monolectals. In contrast, since ETE morphemes were semantically aligned, if an observed effect of Shanghainese morphological probability is mediated by concreteness, the effect should be found consistently across groups.

Hence, this study manipulated the morphological probability of novel compounds in the recipient dialect to investigate whether and at which stage of lexical borrowing the constituents of loan compounds emerge in the mental lexicon of the borrowers.

\section{Conflict Resolution and Inference in Cross-Dialectal Lexical Borrowing}

In the context of cross-dialectal lexical borrowing, conflict resolution and inference were also investigated in this study. Bilinguals are known to show cognitive advantages relative to monolinguals in conflict resolution and attentional control (as reviewed by Bialystok, 2009). However, little is known about whether bilinguals and monolinguals differ in how they infer lexical meanings from the exterior context. Only that the mutual exclusivity principle (Markman, 1992) may work differently by monolingual and bilingual children in some situations (Davidson and Tell, 2005; Kalashnikova et al., 2015), wherein the older

\footnotetext{
${ }^{3}$ This fact has long been noticed by Chinese linguists in their research regarding literary Wen and colloquial Bai lexical variants in Chinese dialects (e.g., You, 2000, pp. 137).
} 
bilingual children are more able to accept lexical overlap, but they are not always different (e.g., see Frank and Poulin-Dubois, 2002).

The current study manipulated the referential context in the comprehension borrowing session to compare the practice of bi-dialectals and monolectals in resolving referential ambiguity during comprehension borrowing. In the preconditioning learning phase of novel SC words, we included some images with no explicit names given but accompanied with white noise. Then in the comprehension borrowing test, trials with auditory words and trials with white noise were included.

First, to test for the effects of conflict resolution, the word trials compared a high-competition context (target image accompanied with a distractor image which had been associated with a word) with a low-competition context (with a distractor image which had been associated with noise). Second, to test for the potential difference between bi-dialectals and monolectals in inferencing lexical references with the mutual exclusivity principle, the noise trials compared an inference-possible context (with a distractor image associated with a word) with an inference-impossible context (with a distractor image also associated with noise).

In sum, the current research adopted a modified experimental neologism paradigm in a SC-SH auditory lexical borrowing experiment by monolectals and bi-dialectals. Both comprehension and production borrowings were tested to investigate the roles of long-term and short-term linguistic experience on lexical borrowing.

\section{MATERIALS AND METHODS}

\section{Participants}

Three groups of participants participated in this experiment in exchange for payment. (1) Native SC monolectals who only speak SC natively and no other Chinese dialects were 28 in total, 4 men and 24 women, age 17-34, $M=21.35, S D=4.04$, self-rated SC proficiency (on a $0-10$ scale) $5 \sim 10, M=8.89, S D=1.22$. The other two groups were bi-dialectals. (2) Standard-ChineseShanghainese bi-dialectals who speak both the source dialect SC and the recipient dialect $\mathrm{SH}$ natively were 37 in total, 13 men and 24 women, age $18 \sim 47, M=24.27, S D=7.13$, self-rated SC proficiency (on a $0-10$ scale) $4 \sim 10, M=8.65, S D=1.37$, SH proficiency $5 \sim 10, M=8, S D=1$. (3) Standard-ChineseOther-Dialects bi-dialectals who speak the source dialect SC and a non- $\mathrm{Wu}^{4}$ Chinese dialect natively were 34 in total, 5 men and 29 women, age $18 \sim 30, M=22.41, S D=2.33$, self-rated SC proficiency (on a $0-10$ scale) $6 \sim 10, M=8.65, S D=1.22$, selfrated $\mathrm{OD}$ proficiency $2 \sim 10, M=7.63, S D=1.97$. The locations of the dialects of SC-OD bi-dialectals are shown on a map of China in Figure 1.

All participants acquired their literacy in SC and learned some English at school. A few participants from each group also had

\footnotetext{
${ }^{4}$ Shanghainese belongs to the $W u$ family of Chinese dialect (Chen and Gussenhoven, 2015). To control for the influence of mutual-intelligibility (Tang and Van Heuven, 2009), SC-OD participants who speak a $W u$ dialect were excluded.
}

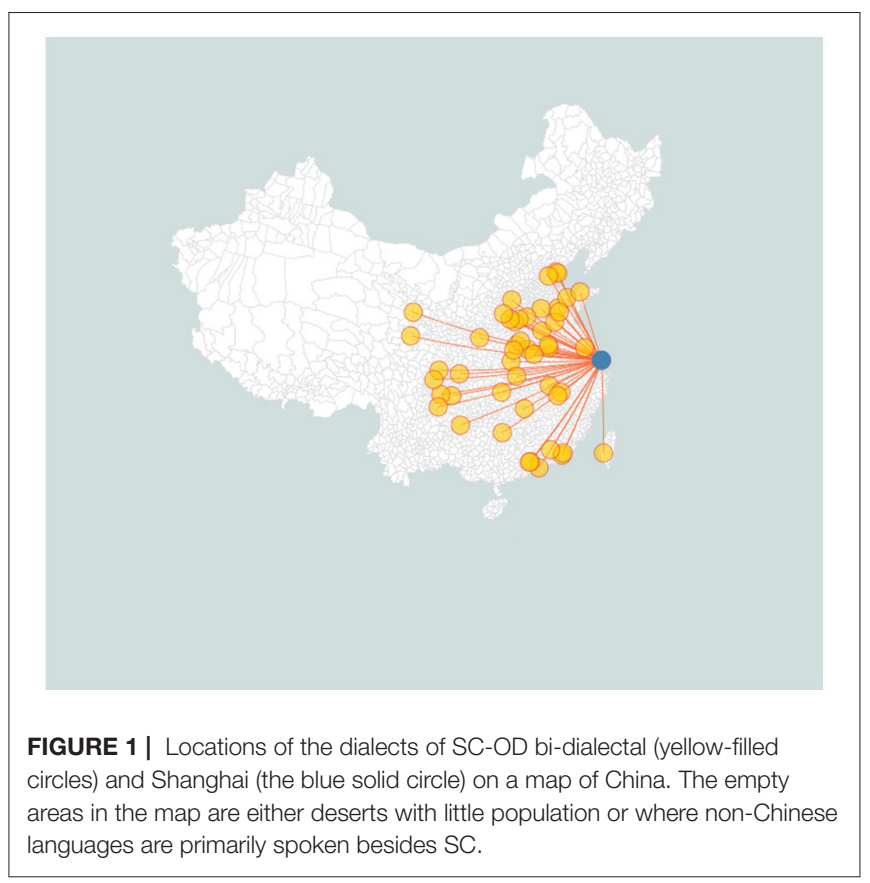

some knowledge of other foreign languages. Due to the limitation of recruiting conditions, all three groups had a long-tail age distribution, skewed to the left (younger side).

\section{Design and Procedure}

This study adopted an experimental neologism paradigm. As shown in Figure 2, first, in a preconditioning phase, participants learned to associate aurally given names (nonce compounds made of existing Chinese morphemes) with images of novel shapes in SC. They were trained with a "choose-one-fromtwo" audio-image lexical identification task in SC until their accumulative accuracy reaches $85 \%$. For images associated with white noise in the learning phase, either choice is taken as correct in the practice phase. Afterwards, they were tested again in both SC and SH with an audio-image lexical identification task (comprehension test) and then an image-naming task (production test).

A mixed design was adopted. (1) Long-term linguistic experience was manipulated between participant groups, which included dialectal background (SC monolectal/SC-SH bi-dialectal/SC-OD bi-dialectal), age, and subjective proficiency in $S C$ of the participants. (2) Short-term linguistic experience were manipulated within groups, including the morphological probability of novel compounds in SH (more/less probable, also corresponding to more/less concrete meanings of the morphemes), cross-dialectal similarity (scaled) between sourcedialect and recipient-dialect forms, and dialect of operation (SC $=$ source dialect $/ S H=$ recipient dialect).

In addition, the design for the auditory identification test also manipulated exterior context provided by the distractor (high/low-competition for the novel words \& inference possible/impossible for the noise). Moreover, for the production 


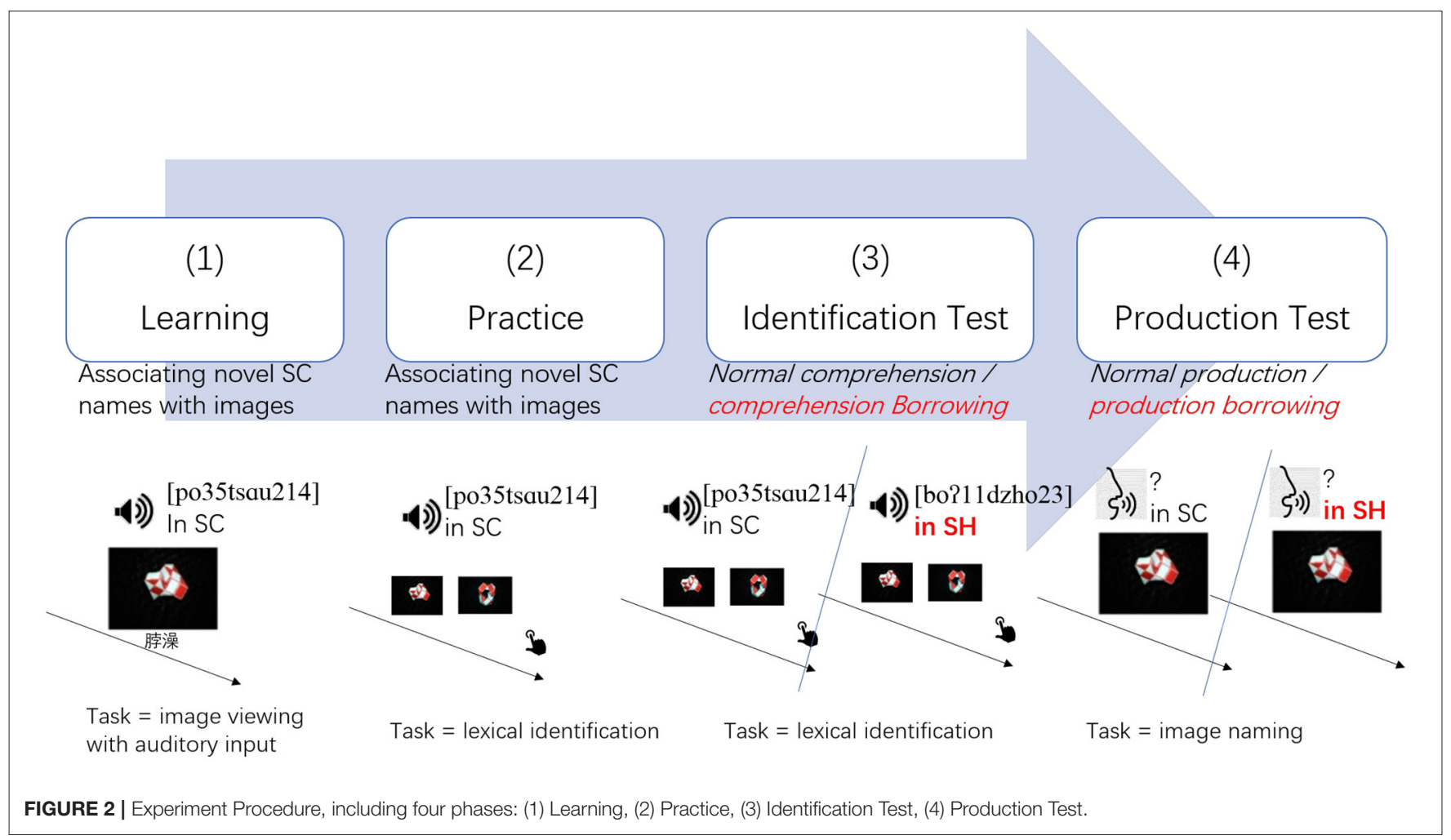

TABLE 2 | Experiment procedure (normal fonts) and the corresponding theoretical implications (bold fonts).

\begin{tabular}{|c|c|c|c|c|c|c|c|}
\hline \multirow{2}{*}{$\begin{array}{l}\text { Phases } \\
\text { Dialect }\end{array}$} & \multirow[t]{2}{*}{ (1) Learning } & \multirow[t]{2}{*}{ (2) Practice } & \multicolumn{2}{|c|}{ (3) Identification test } & \multicolumn{2}{|c|}{ (4) Production test } & \multirow[t]{2}{*}{ Theoretical implications } \\
\hline & & & & & & & \\
\hline Cond. 1 & SC & SC & - & $\mathrm{SH}$ & SC & - & $\begin{array}{l}\text { Backward influence (from } \\
\text { recipient to source dialects) }\end{array}$ \\
\hline Cond. 2 & SC & SC & SC & - & SC & - & Source-dialect baseline \\
\hline Cond. 3 & SC & SC & - & $\mathrm{SH}$ & - & $\mathrm{SH}$ & $\begin{array}{l}\text { Incidentally-established } \\
\text { borrowing }\end{array}$ \\
\hline Cond. 4 & SC & SC & SC & - & - & $\mathrm{SH}$ & Nonce borrowing \\
\hline
\end{tabular}

task, the factor dialect of operation was combined with the exposure of the participants to target words prior to the naming task, which formed a new factor lexical-specific learning experience (bi-dialectal exposure and tested in SC/exposure only in SC and tested in SC/bi-dialectal exposure and tested in SH/ exposure only in SC and tested in $\mathrm{SH}$ ).

As shown in Table 2, during the learning phase each participant was asked to remember four name-image associations in SC. Second, during the identification test after practice, participants were required to identify an aurally presented word by choosing from two given images in each trial. They identified two associations in SC and the other two in $\mathrm{SH}$ (comprehension borrowing). Each participant identified each association twice in each dialect, first with a high-competition context, and then with a low-competition context. Third, in the picture-naming test, participants named one of the two associations which they just identified in SC again in SC and the other in SH. Similarly, they also named one of the two associations which they just identified in $\mathrm{SH}$ and the other in SC. In the naming task, they were first tested in $\mathrm{SC}$ and then in SH. Separate recordings were collected from the onsets of visual stimuli until the beginning of the next visual stimuli.

In the learning phase, participants also learned four images without names (presented with white noises). In the identification test, these noise associations were mixed with associations with names and each association was tested twice, first in inference-possible context, and then in inferenceimpossible context. Participants were told that either image chosen would be treated as correct for the noise trials.

The design avoided presenting names with shared or similar morphemes to the same participant. The same eight images were given to all the participants but were associated with different names for different participants so that more names 
with a wide range of $\mathrm{SH}$ morphological probability can be tested. Each participant group was divided into sub-groups so that name-image associations can be similarly counterbalanced within each group.

After the experimental neologism experiment, all participants rated all the SC-SH name pairs on a five-point scale for the cross-dialectal similarity measurement.

\section{Stimuli \\ Novel Names}

A list of disyllabic novel ETE pairs was composed using a five-step procedure as described in Appendix 1, based on an $\mathrm{SH}$ corpus built by the author ( 0.2 million words, $\mathrm{Wu}$, in preparation ${ }^{5}$, phonology according to Duanmu, 1999; You, 2013; Zhang and Meng, 2016). The list contained 16 pairs of SH-more-probable and 16 pairs of SH-less-probable ETEs (see Appendix 2). A Standard-Chinese-Shanghainese bi-dialectal male speaker read the list, once in SH and once in SC, yielding 64 recordings, of which silent parts were trimmed. The morpheme frequencies and cross-dialectal similarities are demonstrated in the upper and middle panels of Figure 3.

\section{Novel Images}

Eight novel shapes were generated with a 24-piece foldable toy (a Magic Stick, visual, and conceptual complexities controlled), shot with fixed distance, angle, and illumination, yielding eight different images as shown in the lower panel of Figure 3.

\section{Chinese Written Forms (Learning Phase Only)}

In the learning phase, in addition to the aurally given novel names and associated images, ideographic Chinese characters for the novel names were also given. They were included because both SH and SC have too many homophonic morphemes (but written with different characters) and the experimental manipulation requires the specific morphemes to be activated during the learning phase.

\section{Pre-processing of Naming Data}

A sound-pressure-based Praat script (Praat software (), Boersma, 2002; a post-hoc voice key, adapted from Pacilly, 2010) was used to automatically detect the start and the end of speech in each recording, which was later screened and corrected. Response (whether or not a participant gave a response for a given trial) and accuracy were also marked.

\section{RESULTS}

Since the (subjective) cross-dialectal similarity data were used in the modeling of identification and naming data, they were first analyzed in Cross-Dialectal Similarity sections. Accuracies and Reaction Times in the Identification Task and Response Rates, Accuracies, and Reaction Times in the Naming Task sections examined responses in the identification and naming task, respectively.

${ }^{5} \mathrm{Wu}$, J. (in preparation). Natural Text Corpus of Shanghainese.

\section{Cross-Dialectal Similarity}

First, to test the influence of dialectal background on crossdialectal similarity rating data, Gaussian Linear Mixed Effect (LME) models (Bates et al., 2013; R Core Team, 2019) were built on raw and by-participant-normalized data. Participant and word as random intercepts were both highly significant, $\chi_{\text {raw } \sim 1 \mid \text { participant }}^{2}=3149.5$, p1|participant $<0.001$, $\chi_{\text {raw } \sim 1 \mid \text { word }}^{2}=721.95, \quad p_{1 \mid \text { word }}<0.001, \chi_{\text {norm } \sim \mid \text { participant }}^{2}=$ $280.74, p_{\text {norm } \sim 1 \mid \text { participant }}<0.001, \chi_{1 \mid \text { word }}^{2}=770.33, p_{1 \mid \text { word }}$ $<0.001$. Neither group of bi-dialectals differed significantly from the monolectals in their overall effect of cross-dialectal rating, whether with raw ratings, $t_{\text {raw } \sim S C-S H b i-\text { dialectal }}(0.22)$ $=0.53, p=0.6, t_{\text {raw } \sim S C-O D b i-\text { dialectal }}(0.22)=0.91, p=0.38$, or by-participant normalized ratings, $t$ norm $\sim S C-S H b i-$ dialectal $(0.05)=1.06, p=0.29, t_{\text {norm } \sim S C}-$ ODbi-dialectal $(0.05)=0.82$, $p=0.41$. Post-hoc Least Square Contrasts from lmerTest package (Kuznetsova et al., 2013) also confirmed the absence of group-dependent overall difference on similarity ratings.

Second, based on the by-participant-normalized rating data, separate values of cross-dialectal similarity were calculated for each pair of novel ETEs, as shown in Figure 4. The average crossdialectal similarity data for each pair of ETEs showed strong bypair Pearson correlations across all three participant groups, $R$ SCmonolectal $\sim S C-S H b i-$ dialectal $=0.78, R$ SCmonolectal $\sim S C-O D b i-$ dialectal $=0.89, R S C-S H b i-$ dialectal $\sim S C-O D b i-$ dialectal $=0.87$, indicating high consistency across groups. Figure 4 also shows standard deviations of ratings calculated across groups for each ETE pair with color depth, which indicate the consistency of ratings across groups.

Considering the high consistency across groups, scaled mean cross-dialectal similarity was calculated for each pair of SC-SH novel ETEs and used as a predictor in the following analysis. Three pairs of ETEs (as marked with light gray in the middle panel of Figure 3) were excluded from the analyses to make the distribution of cross-dialectal similarity more comparable between the SH-more-probable and SH-less-probable sets.

\section{Accuracies and Reaction Times in the Identification Task}

We analyzed accuracies (whether each aurally presented stimulus was correctly identified with its corresponding image) and $\log$ RTs (reaction times which were natural-log-transformed to improve the distribution) of the correct responses from the identification task with logistic and Gaussian LME models, respectively (Bates et al., 2013). The models included scaled mean cross-dialectal similarity for each pair of SC-SH novel words (hereafter referred to as cross-dialectal similarity), the morphological probability of the novel word in SH (more/less probable, also corresponding to more/less concrete meanings of the morphemes), a dialect of operation ( $\mathrm{SC}=$ source dialect, $\mathrm{SC} / \mathrm{SH}=$ recipient dialect, $\mathrm{SH}$ ), the exterior context provided by the distractor (high/low-competition for the word trials and inference possible/impossible for the noise trials), and dialectal background of the participant (SC monolectal/SC$\mathrm{SH}$ bi-dialectal/SC-OD bi-dialectal) as fixed predictors and included them in all the candidate-models. Besides these crucial 
A

candidate mono-syllabic morphemes (represented with characters)

color $=$ (likelyhood as beginning char in SC)

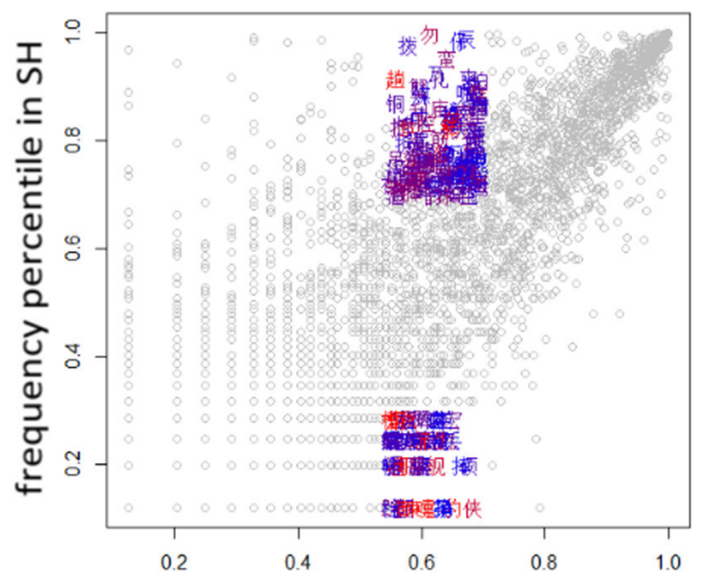

color $=($ likelyhood as final char in SC)

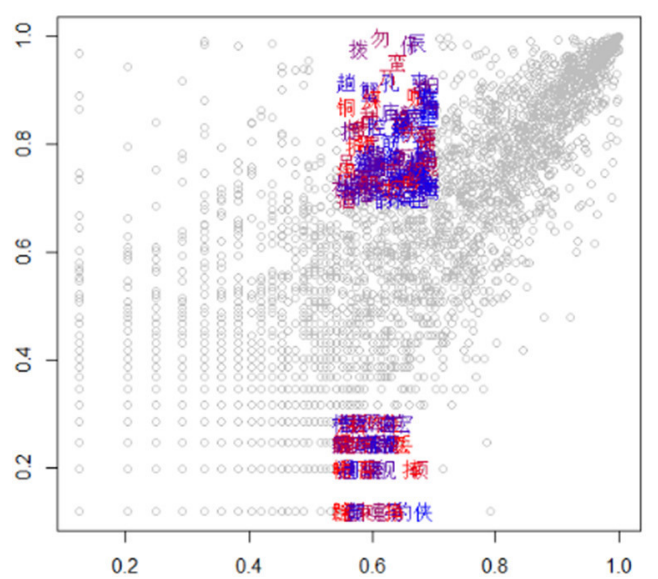

B

敨

frequency percentile in SC

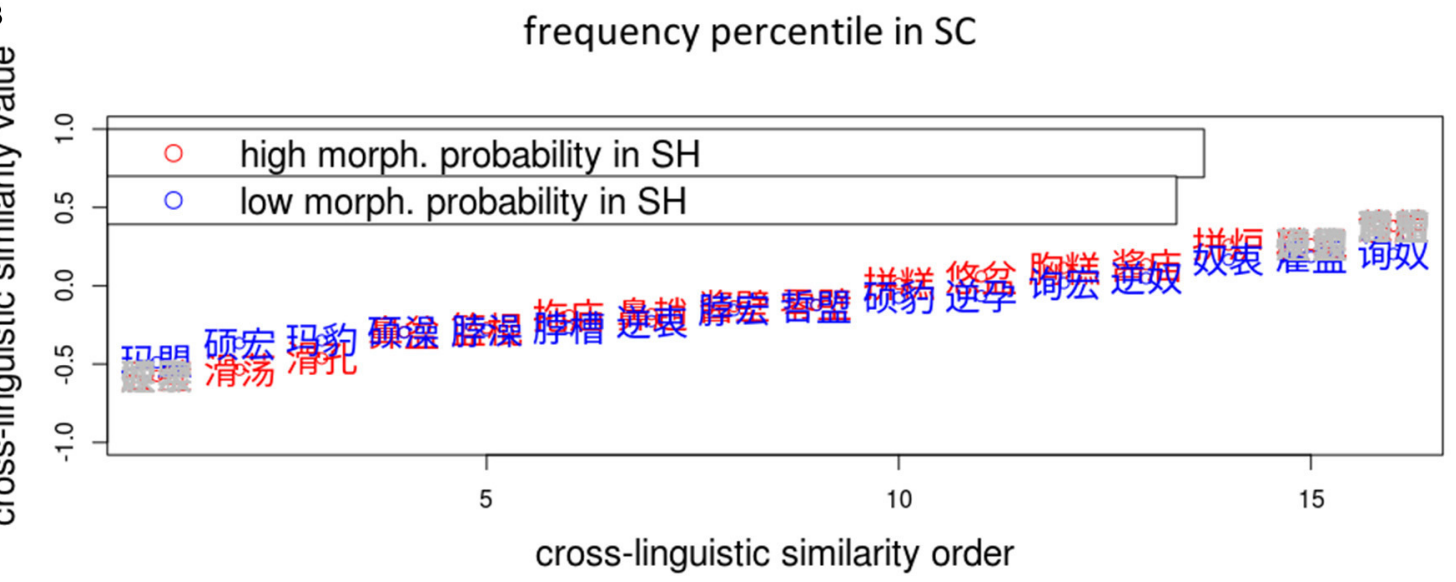

C
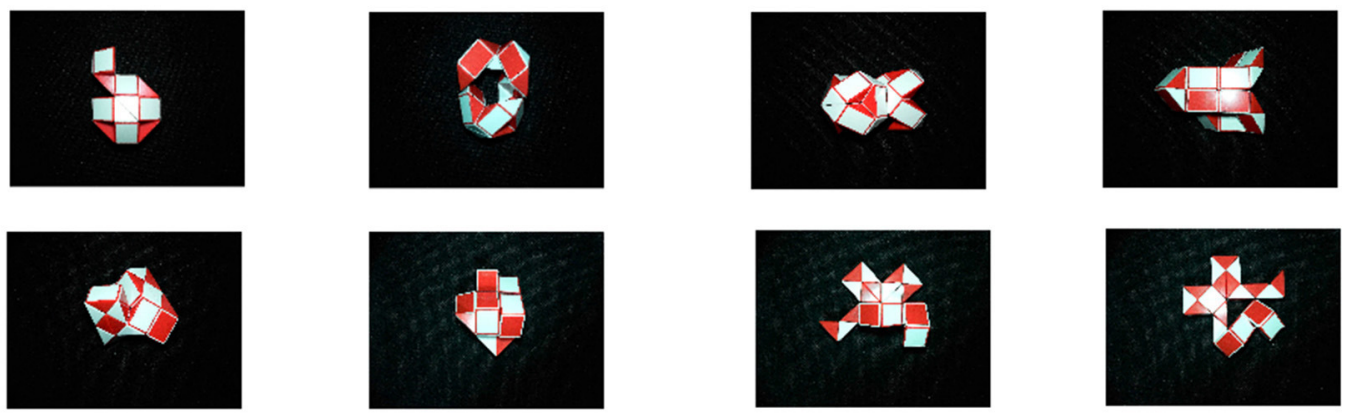

FIGURE 3 | (A) Upper panel: scattered plots for candidate mono syllabic ETE morphemes, represented with Chinese characters, plotted with frequency percentiles in SC (along the horizontal axis) and SH (along the vertical axis), colored from blue (low) to red (high), according to the likelihood as beginning (left sub-plot) and final characters (right sub-plot). (B) Middle panel: scattered plots for two sets of disyllabic novel ETE pairs, represented with Chinese characters, plotted with the order (along the horizontal axis) and values (along the vertical axis) of cross-dialectal similarity, colored in blue for low morphological probability and in red for high morphological probability. Three pairs with extreme values of cross-dialectal similarity mismatching between sets were excluded from the analysis (colored in light gray). (C) Lower panel: images of unfamiliar shapes.

predictors, their possible interactions, as well as sociolinguistic predictors, i.e., the scaled age and scaled subjective proficiency of the participants in SC, and their multi-way interactions were also included as candidates of fixed predictors. By-participant random intercepts (nested under dialectal background or not), by-word random intercepts (nested under morphological probability in 


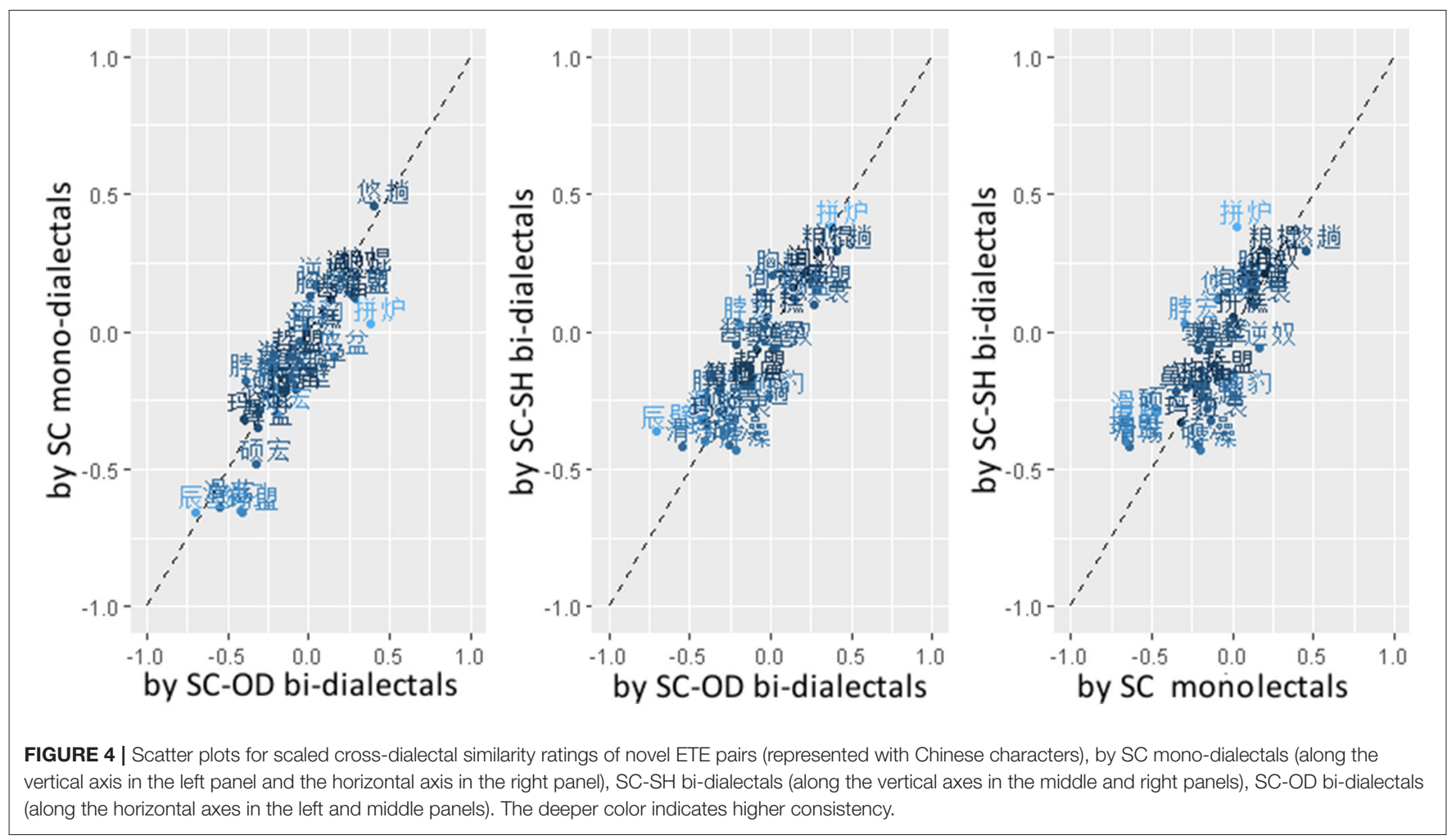

$\mathrm{SH}$ or not), by-target-image random intercepts, and by-distractorimage random intercepts were included as the candidates for the random terms. Since the stimuli were counterbalanced across participants to control the repetition of the same novel words, no random slope was possible in the modeling. The structure of the terms in the models reported here was selected via model comparison based on Akaike's Criteria (Sakamoto and Ishiguro, 1986). In the process of model comparison, the main effects of the crucial predictors were always included, while the other fixed and random terms were allowed to be excluded according to the result of the model comparison. The model estimates were calculated with the lsmeans function from the lmerTest package (Kuznetsova et al., 2013).

Responses to words and noises were analyzed separately, as the corresponding mental mechanisms were very different. We here first present results for words.

\section{Responses to Word Trials in the Identification Task}

(1) For the accuracy model (logistic LME), the selected random predictors were by-participant and by-target-image random intercepts, $\chi 2_{1 \mid \text { participant }}=144.94, p_{1 \text { participant }}<0.001$, $\chi 2_{1 \mid \text { target-image }}=19.86, p_{1 \mid \text { target-image }}<0.001$. The crucial terms were all kept according to the design. $\mathrm{SH}$ as dialect of operation, $z_{\text {sH(borrowing })}=-3.71, p<0.001$, older age, $z_{\text {sH(olderage })}=$ $-2.63, p<0.05$, and smaller morphological probability in $\mathrm{SH}$ (less concrete meanings), $z_{\text {lessprob.(lessconcrete) }}=-2.17, p<0.05$, have significant negative main effects on accuracies. $S C-S H$ dialectal background, $z S C-S H b i-$ dialectal $=2.70, p<0.05$, and low-competition context, $z$ low-competition $=10.98, p<0.001$, have positive main effects on accuracies. Main effects of the other predictors were insignificant. The only significant interaction was between smaller morphological probability in $\mathrm{SH}$ (less concrete meanings) and cross-dialectal similarity, $z$ lessprob.(lessconcrete) : similarity $=2.25, p<0.05$. All the conditions yielded accuracy rates above $70 \%$, as shown in the left panel of Figure 5.

Since some of the SC-SH bi-dialectals were older, separate logistic-LME models were built again for participants with different dialectal backgrounds to further investigate the age effect. Although the effect of age was consistently negative for all three groups, it only reached significance for the SC monolectals, $z_{\text {SCmonolectals : age }}=-2.51, p<0.05$, and did not reach significance for the SC-SH bi-dialectals, $z$ SC-SHbi-dialectals: age $=-1.87, p$ $=0.06$ (marginally significant), or the SC-OD bi-dialectals, $z$ $S C-$ ODbi-dialectals : age $=-0.77, p=0.06$. Also, after excluding the data from the SC-SH bi-dialectals who were older than the oldest of the other two groups, the age effect within this group turned totally insignificant, $z_{S C-S H b i-\operatorname{dialectals}(y o u n g)}$ :age $=-0.3, p=0.77$. Thus, bi-dialectals were less affected by age than monolectals.

(2) For the RT data of the correctly identified trials, statistics of LME models are shown in Appendix 3 with Satterthwaite approximation (Kuznetsova et al., 2013). The model estimates (lsmeans function, lmerTest package, Kuznetsova et al., 2013) are demonstrated in Figure 6.

As shown in the right panel of Figure 6, the three-way interaction across the dialectal background, morphological 

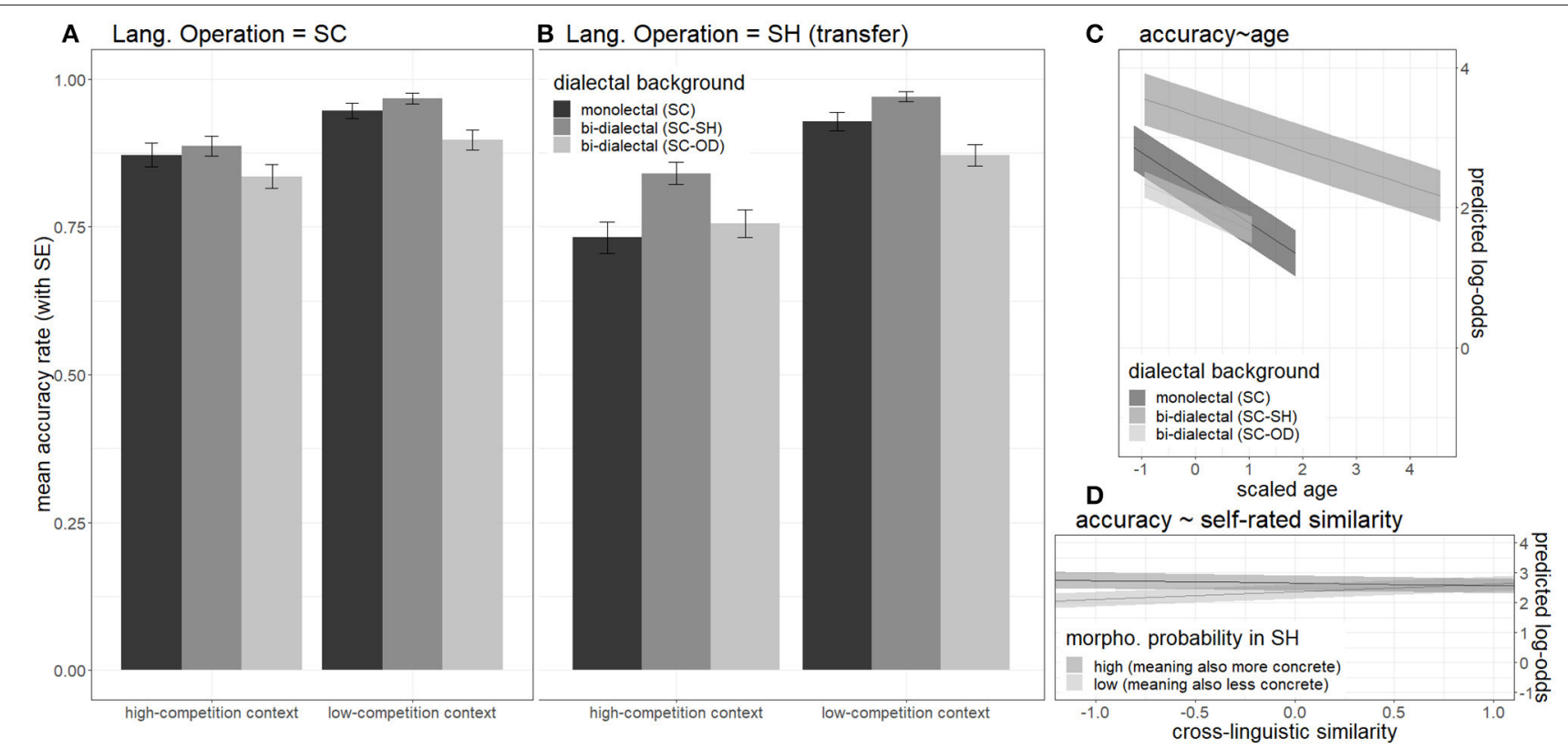

FIGURE 5 | Effects on mean accuracy rates in response to word trials during lexical identification test, including (1) effects of dialectal background (color) and context provided by the distractor (cluster), in SC (A) (left panel) and SH (B) (middle panel), (2) the effect of age (C) (upper right panel), and (3) the interaction between subjective cross-dialectal similarity and semantic concreteness (D) (lower right panel).

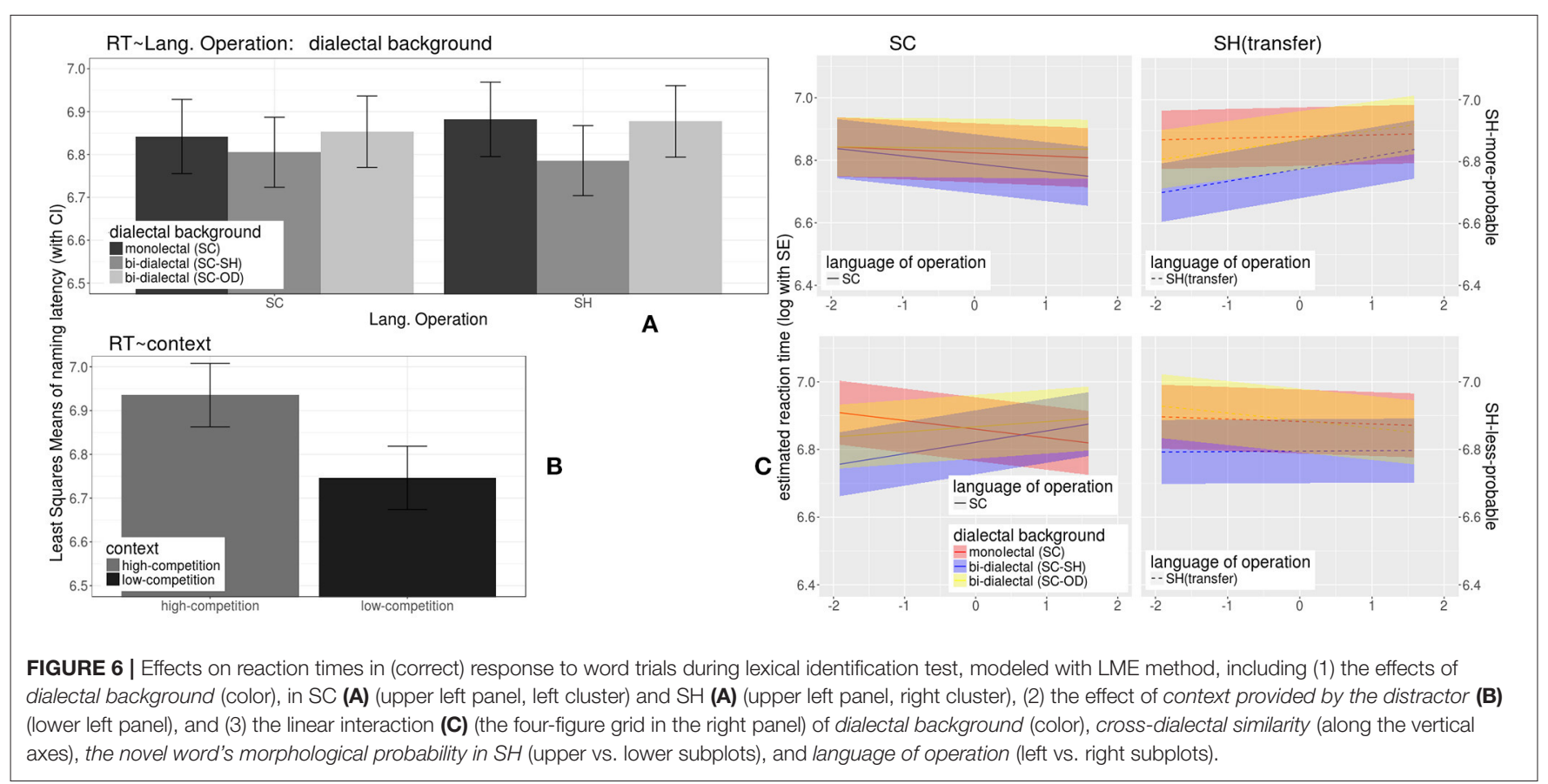

probability in $\mathrm{SH}$ (also reflecting concreteness), and crossdialectal similarity were complicated and subtle, with large variation along the similarity dimension. Thus, Generalized Additive Models (GAMs) were built using the "mgcv" package (Wood, 2006, 2011) in R (R Core Team, 2019) to investigate the potential nonlinear interactions between these predictors. The candidate models included $\log R T s$ as the dependent variable, and linear and smooth predictors were included, as described in more detail in the following.

Smooth functions were used to model non-linear functional relations between RTs and cross-dialectal similarity. The factorial 
predictors, namely dialectal background, dialect of operation, and the novel word's morphological probability in SH (also reflecting concreteness) were combined into a twelve-level predictor (SC monolectal/SC-SH bi-dialectal/SC-OD bi-dialectal $\times \mathrm{SC} / \mathrm{SH} \times$ more/less probable) and this new predictor was included in both the fixed linear predictors and fixed smoothes. Besides this crucial predictor, the context provided by the distractor was also included as a fixed linear predictor. The candidates for random predictors were participant, word, target-image, and distractor-image. The structure of the final model was decided by model comparison based on the Akaike Information Criterion likelihood values (Sakamoto and Ishiguro, 1986). After the structure of the model was decided, auto-correlation values were calculated based on the trial order of data points, which turned out to be close to 0 . Thus, there was no need to build an AR1 error model (Wood, 2006, 2011). The coefficients for the parametric predictors and the $F$ statistics for the smooth terms are shown in Table 3. The results are depicted in Figures 6, 7.

None of the parametric coefficients in Table 3 was significant. Only SC-SH bi-dialectals' RTs to more probable SH trials were marginally shorter than average, $t=-1.65, p=0.1$, and SC-OD bi-dialectals' RTs to less probable $\mathrm{SH}$ trials were marginally longer than average, $t=1.82, p=0.07$.

However, when the dialect of operation was $\mathrm{SH}$ (i.e., under the condition of borrowing), as shown by the colored curves and bands (Van Rij et al., 2015) in Figure 7 and by the F-statistics for the smooth terms in Table 3, while monolectals showed no sensitivity to cross-dialectal similarity in all the correct trials, the two groups of bi-dialectals' RTs in correct $\mathrm{SH}$ trials were influenced by cross-dialectal similarity in a non-linear way, F SC-SHbi-dialectal:more-prob. (1) $=6.11, \quad p \quad 0.05, \quad F \quad$ SC-SHbi-dialectal: less-prob. $(2.52)=$ 2.37, $p=0.06, \quad F \quad S C-O D b i-$ dialectal: more-prob. $(1)=3.561$, $p=0.06, F \quad S C-$ ODbi-dialectal $:$ less-prob. $(3.19)=3.36$, $p<0.05$.

Since the F-statistics for the smooth terms compares each manipulation level with the average level, the two bi-dialectal groups were further compared with the monolectal group posthoc. The estimated differences were depicted in Figure 8 using the plot_diff function from itsadug $\mathrm{R}$ package (Van Rij et al., 2015). The parts of the curves showing significant differences between bi-dialectals and monolectals were marked with vertical dash lines.

In response to morphologically more probable $\mathrm{SH}$ stimuli, SC-SH bi-dialectals' RTs increased with cross-dialectal similarity, while their responses to morphologically less probable $\mathrm{SH}$ stimuli showed a concave shape of nonlinear correlation with cross-dialectal similarity. SC-OD bi-dialectals also showed non-linear patterns (yellow lines and bands in Figures 6, 7), which did not reach significance but are shape-wise more in line with SC-SH bi-dialectals than with SC monolectals.

Taking together the results reported in Responses to Word Trials in the Identification Task section and Figures 4-7, in the identification test, some effects took place by all three groups of participants. (1) All three groups were able to identify the referent of loan forms in SH with considerable accuracy. (2) Age showed a negative effect on accuracies but did not affect RTs of correct responses. (3) All three groups responded more accurately to more concrete words. (4) All three groups gave less accurate responses to the $\mathrm{SH}$ loan forms than to the original SC forms. (5) Low-competition context increased accuracies and reduced RTs.

The three groups of participants showed significant differences in SH, namely under the condition of crossdialectal borrowing. (6) Only non-SH participants took longer to correctly identify $\mathrm{SH}$ forms (novel loanwords) than SC form (source forms). In contrast, SC-SH bi-dialectals were even slightly faster when responding to $\mathrm{SH}$ forms. (7) SC monolectals showed no sensitivity to cross-dialectal similarity regardless of a dialect of operation. In contrast, the bi-dialectals were not sensitive to a cross-dialectal similarity in SC but turned sensitive when the dialect of operation switched to $\mathrm{SH}$ (comprehension borrowing). Also, only the bi-dialectals showed non-linear interactions between cross-dialectal similarity and morphological probability (lower right panel of Figure 8).

\section{Responses to Noise Trials in the Identification Task}

Regarding the noise trials, for the accuracy model, the selected random predictors were by-participant and by-distractor-image random intercepts, $\chi_{1 \mid \text { participant }}^{2}=89.49$, p1|participant $<0.001$, $\chi_{1 \mid \text { distractor-image }}^{2}=4.81, p_{1 \mid \text { distractor-image }}<0.001$. SC-OD bidialectal background, $z_{S C-O D b i-\text { dialectal }}=-3.29, p<0.001$, older age, $z$ age $=-3.72, p<0.001$, and inference-impossible context, $\mathrm{z}$ inferenceimpossible $=-6.03, p<0.001$, showed significant negative main effects on accuracies. Main effects of the other predictors were insignificant. Inference-impossible context had a significant negative interaction with SC-OD as dialectal background, $z$ inferenceimpossible: $S C-O D b i-$ dialectal $=-3.53, p<0.001$, as well as a significant positive interaction with age, $z$ inferenceimpossible: age $=4.67, p<0.001$. The three-way interaction across inferenceimpossible context, SC-OD as dialectal background, and age was also significant, $z$ inferenceimpossible: $S C-O D b i-$ dialectal $:$ age $=-2.19$, $p<0.05$.

As shown in the lower-left panel of Figure 9, given an inference-possible context, all groups' mean accuracies were above $60 \%$, which in contrast dropped to chance level (about $50 \%$ ) when the context was inference-impossible. Accuracies in noise trials dropped with the increase of age, but also only when the context was inference-possible (upper left panel of Figure 9).

For the RT data of correct noise trials, the selected random predictors were by-participant and by-word random intercepts, $\chi_{1 \mid \text { participant }}^{2}=1033.30, p_{1 \mid \text { participant }}<0.001, \chi_{1 \mid \text { word }}^{2}$ $=3.43, p_{1 \mid \text { word }}=0.06$. $S H$ as dialect of operation, $t_{S H \text { (borrowing) }}$ $(2252.41)=-3.03, p<0.001$, as well as inference-impossible context, $t_{\text {inferenceimpossible }}(2245.50)=-11.54, p<0.001$, showed significant main effects in reducing RTs. As shown in the right panel of Figure 9, all groups took longer to respond when inference was possible and when dialect of operation was SC.

Taken together, most effects in the noise trials were insensitive to the participants' dialectal backgrounds. The only 
TABLE 3 | GAM model results for recognition data.

Formula: RTadjusted_log $\sim$ s(Similarity, by = LanBGLanOpMfreq_Tst, $\mathrm{k}=18)+$ LanBGLanOpMfreq_Tst + Context + s(Similarity, Participant, bs $=$ "fs", $\mathrm{m}=1)+$ $s($ Word, bs = "re") $+s($ Targetlmg, bs = "re")

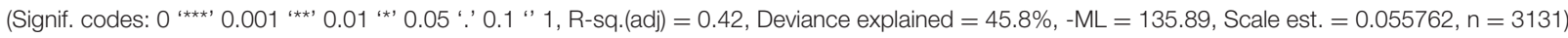

- LanBGLanOpMfreq_Tst: a combined predictor of dialectal background, dialect of operation, and the novel word's morphological probability in SH (also

reflecting concreteness)

- Similarity: cross-dialectal similarity

- Context: context provided by the distractor

- Participant: participant

- Word: word

- Targetlmg: target-image

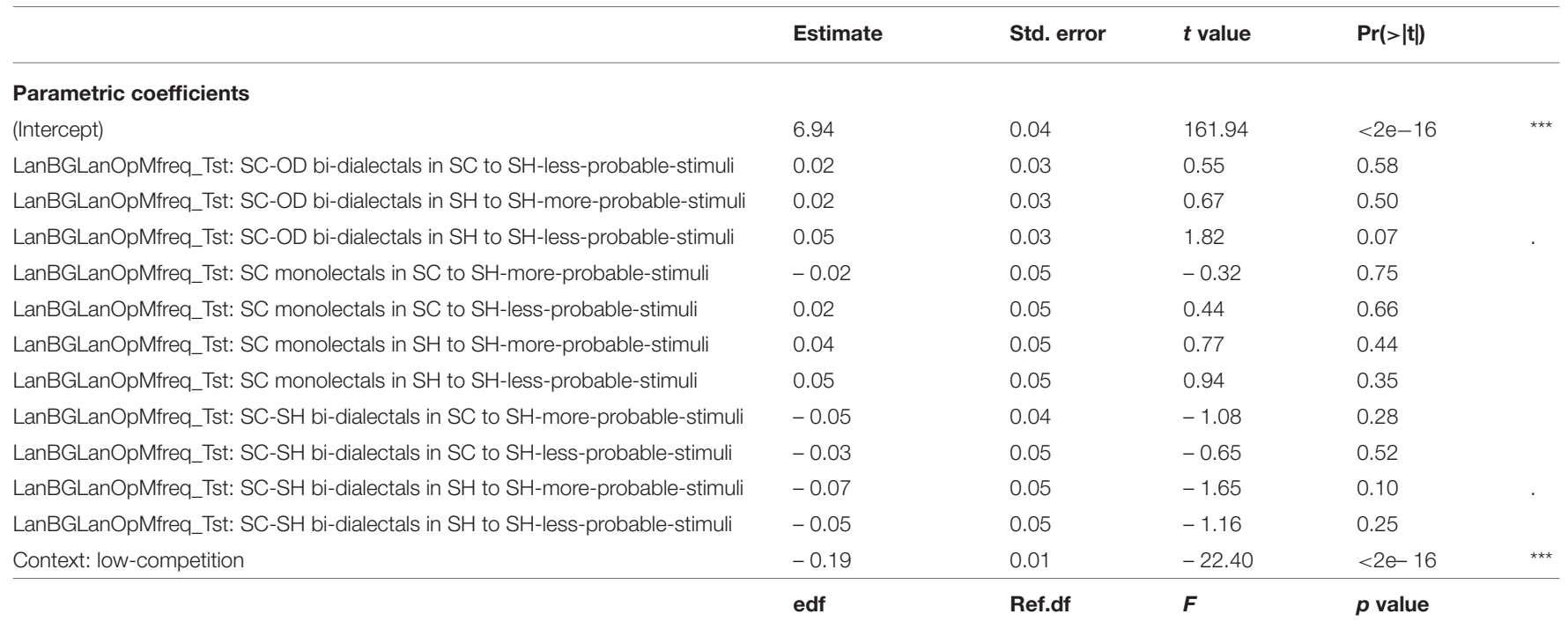

\section{Approximate significance of smooth terms}

s(Similarity) by LanBGLanOpMfreq_Tst: SC-OD bi-dialectals in SC to $\mathrm{SH}$-more-probable-stimuli

s(Similarity) by LanBGLanOpMfreq_Tst: SC-OD bi-dialectals in SC to SH-less-probable-stimuli

s(Similarity) by LanBGLanOpMfreq_Tst: SC-OD bi-dialectals in SH to $\mathrm{SH}$-more-probable-stimuli

s(Similarity) by LanBGLanOpMfreq_Tst: SC-OD bi-dialectals in SH to SH-less-probable-stimuli

$\mathrm{s}$ (Similarity) by LanBGLanOpMfreq_Tst: SC monolectals in SC to

$\mathrm{SH}$-more-probable-stimuli

$\mathrm{s}$ (Similarity) by LanBGLanOpMfreq_Tst: SC monolectals in SC to

SH-less-probable-stimuli

s(Similarity) by LanBGLanOpMfreq_Tst: SC monolectals in SH to

SH-more-probable-stimuli

s(Similarity) by LanBGLanOpMfreq_Tst: SC monolectals in SH to

SH-less-probable-stimuli

s(Similarity) by LanBGLanOpMfreq_Tst: SC-SH bi-dialectals in SC to

SH-more-probable-stimuli

s(Similarity) by LanBGLanOpMfreq_Tst: SC-SH bi-dialectals in SC to

SH-less-probable-stimuli

s(Similarity) by LanBGLanOpMfreq_Tst: SC-SH bi-dialectals in SH to

SH-more-probable-stimuli

s(Similarity) by LanBGLanOpMfreq_Tst: SC-SH bi-dialectals in SH to

SH-less-probable-stimuli

$\mathrm{s}$ (Similarity, Participant)

$s($ Word)

s(Targetlmg)

\begin{tabular}{|c|c|c|c|c|}
\hline 1.00 & 1.00 & 0.00 & 0.99 & \\
\hline 1.00 & 1.00 & 0.16 & 0.69 & \\
\hline 1.00 & 1.00 & 3.56 & 0.06 & . \\
\hline 2.75 & 3.19 & 3.36 & 0.02 & * \\
\hline 1.00 & 1.00 & 0.25 & 0.62 & \\
\hline 1.00 & 1.00 & 0.19 & 0.66 & \\
\hline 1.00 & 1.00 & 0.01 & 0.94 & \\
\hline 1.00 & 1.00 & 0.37 & 0.54 & \\
\hline 1.00 & 1.00 & 0.60 & 0.44 & \\
\hline 1.00 & 1.00 & 0.72 & 0.40 & \\
\hline 1.00 & 1.00 & 6.11 & 0.01 & * \\
\hline 2.17 & 2.52 & 2.37 & 0.06 & . \\
\hline 161.42 & 334.00 & 5.62 & $<2 \mathrm{e}-16$ & 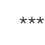 \\
\hline 9.85 & 25.00 & 1.02 & 0.00 & $\star \star \star *$ \\
\hline 6.50 & 7.00 & 25.09 & $<2 \mathrm{e}-16$ & $\star \star * *$ \\
\hline
\end{tabular}




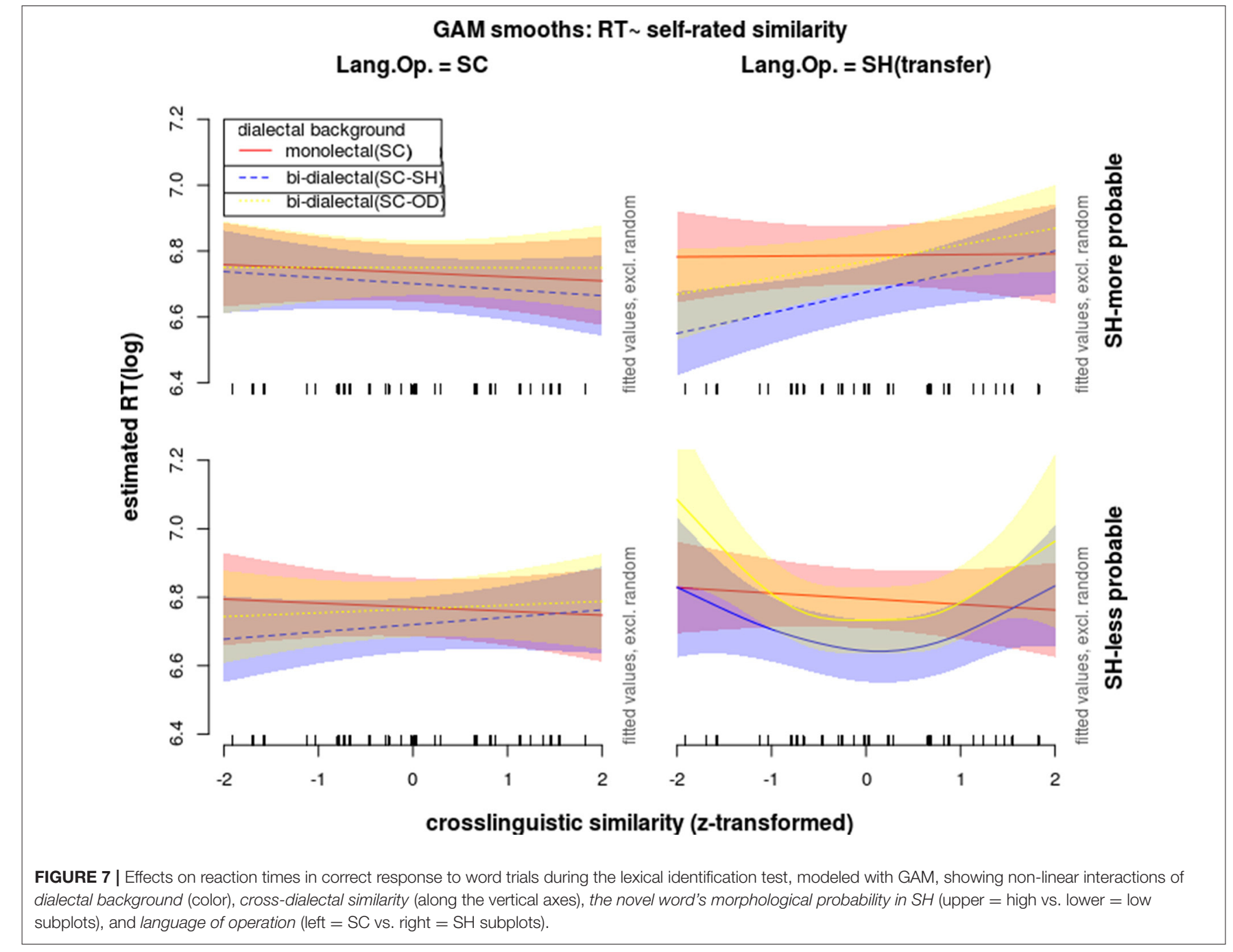

significant effect of dialectal background was that SC-OD bidialectals were less accurate than SC monolectals and SC$\mathrm{SH}$ bi-dialectals in inference-possible context. However, they showed no difference from the other two groups when inference was impossible.

\section{Response Rates, Accuracies, and Reaction Times in the Naming Task}

As noted in Holistic Casting versus Morpheme-Based ReEncoding in Lexical Borrowing section, the experiment compared four conditions of prior short-term exposure conditions (learning experience), where the participants had either bi-dialectal or monolectal exposure to the target words prior to the naming and were tested either in SC or SH. Hence, besides the crucial predictors which were also tested with the identification data, one additional predictor, learning experience, was included in models for the naming data. All the other settings were identical to Accuracies and Reaction Times in the Identification Task section.

\section{Response Rates in the Naming Task}

Regarding whether or not participants gave responses in the naming task, the selected random predictors were by-participant and by-target-image random intercepts, $\chi_{1 \mid \text { participant }}^{2}=66.51, p_{1 \mid \text { participant }}<0.001, \quad \chi_{1 \mid \text { target-image }}^{2}=$ $60.95, \quad p_{1 \mid \text { target-image }}<0.001$.With incidental bi-dialectal exposure and tested in SC as the base-line (i.e., compared with the richest lexical experience plus the easiest testing condition), monolectal learning experience significantly reduced response rates, whether the test dialect was SC or $\mathrm{SH}$ (indirect exposure), $z$ exposureonlyinSC\&testedinSC $=-2.60$, $p<0.05, z$ exposureonlyinSC\&testedinsH $=-5.67, p<0.001$. Regarding dialectal background, SC-SH bi-dialectals were more likely to give responses than SC monolectals, $\mathrm{Z}$ $S C-S H b i-$ dialectal $=3.87, p<0.001$; however, they were less likely to give responses to $\mathrm{SH}$ less-probable words than to $\mathrm{SH}$ more-probable words, $\mathrm{z}$ SC-SHbi-dialectal: SHless-prob. $=-2.07$, $p<0.05$.

As shown in Figure 10, except for the indirect exposure condition, mean response rates were 


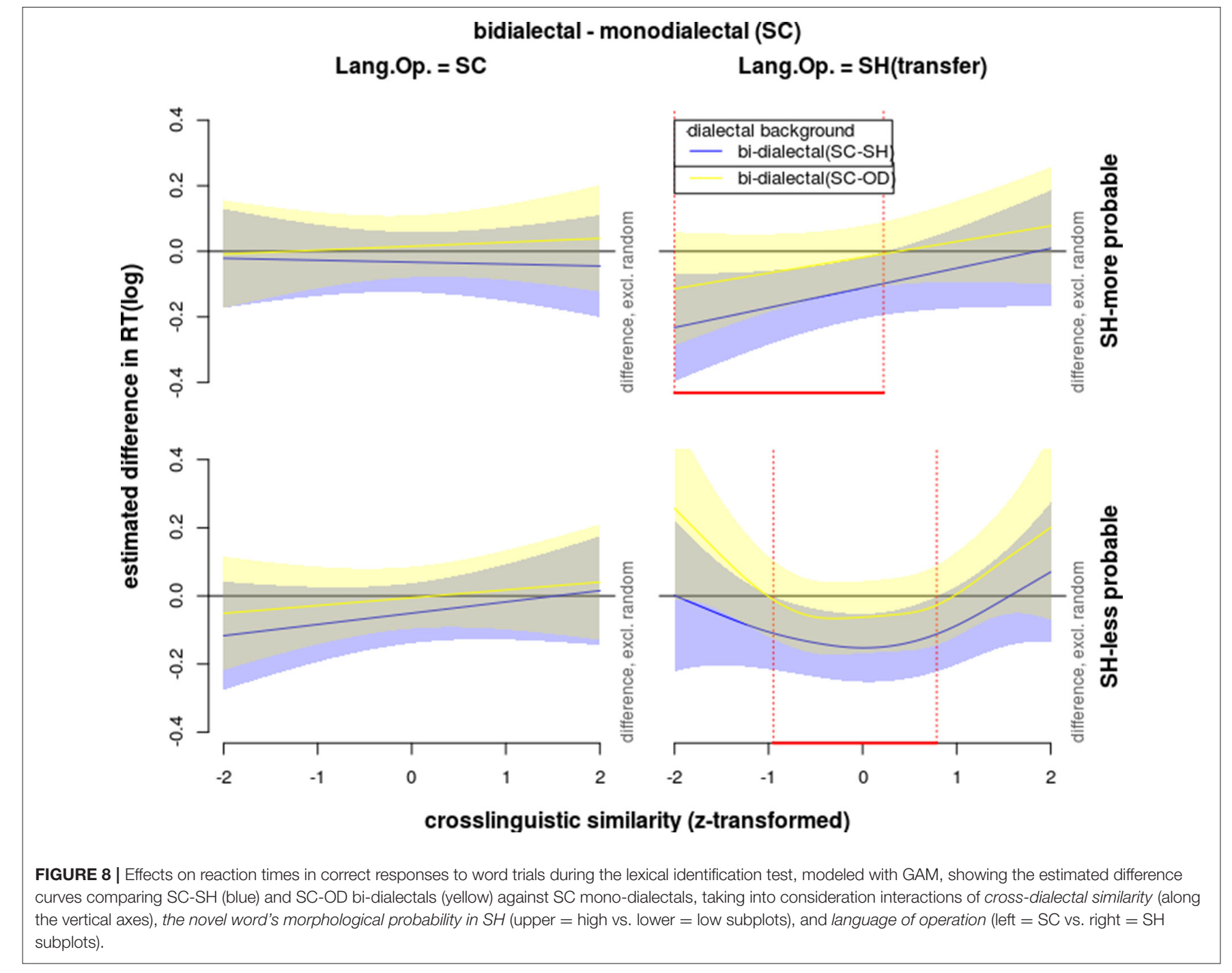

all above 0.5 across conditions. Note that SC$\mathrm{SH}$ bi-dialectals were the only group whose responses rates were significantly influenced by morphological probabilities.

\section{Accuracies in the Naming Task}

Regarding accuracy during naming, the selected random predictors were by-participant, by-word, and by-targetimage random intercepts, $\chi_{1 \mid \text { participant }}^{2}=83.84, p_{1 \mid \text { participant }}$ $<0.001, \chi_{1 \mid \text { word }}^{2}=4.10, p_{1 \mid \text { word }}<0.05, \chi_{1 \mid \text { target-image }}^{2}=60.20$, $p_{1 \mid \text { target-image }}<0.001$. SH-less-probable and also less-concrete targets elicited less accurate responses across all three groups, $\mathrm{z}_{\text {less-prob.(lessconcrete) }}=-2.80, p<0.01$, hence this is mainly an effect of concreteness. With bi-dialectal exposure and tested in SC as the base-line, $\mathrm{SH}$ as dialect of operation significantly reduced accuracy, $z$ bi-dialectalexposure\&testedinSH $=-2.12, p$ $<0.05, \mathrm{Z}$ exposureonlyinSC\&testedinSH(indirectexposure) $=-6.27, \quad p$ $<0.001$. However, SC-SH bi-dialectal background showed a significant positive interaction with indirect exposure, $z$
SC-SHbi-dialectal: exposureonlyinSC\&testedinSH(indirectexposure) $=3.13$, $p<0.001$.

As shown in Figure 11, long-term $\mathrm{SH}$-specific background is critical for production accuracy. (1) $S H$ as dialect of operation significantly reduced non-SH participants' but not SC-SH bi-dialectals' naming accuracy. (2) While bidialectal exposure significantly increased accuracy across all participant groups, unlike the non-SH groups, $\mathrm{SC}-\mathrm{SH}$ bidialectals suffer little from the lack of prior direct exposure to the target $\mathrm{SH}$ forms, especially when $\mathrm{SH}$ morphological probability was high. (3) Regarding non-SH groups, lower concreteness reduced their mean accuracies only in SC but not in SH. In contrast, SC-SH bi-dialectals named SH-moreprobable words more accurately than SH-less-probable words in both dialects.

\section{Reaction Times in the Naming Task (i.e., Naming Latencies)}

Regarding RTs in correct naming, the selected random predictors were by-participant, by-word, and by-target-image 


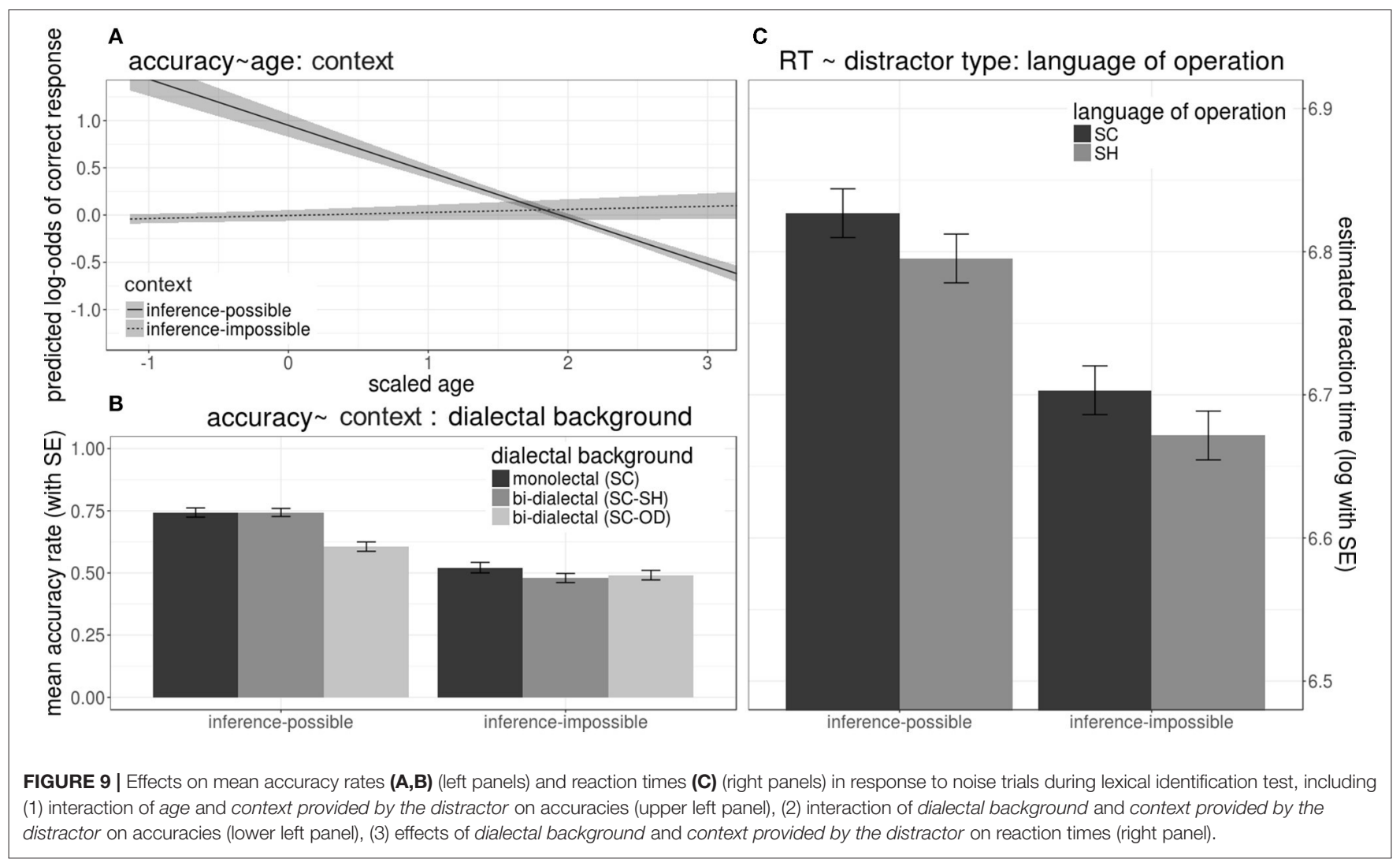

random intercepts, $\chi 2_{1 \mid \text { participant }}=3.60, p_{1 \mid \text { participant }}=0.06$, $\chi 2_{1 \mid \text { word }}=5.63, p_{1 \mid \text { word }}<0.05, \quad \chi 2_{1 \mid \text { target-image }}=31.16$, $p_{1 \mid \text { target-image }}<0.001$. With bi-dialectal exposure and tested in SC as the base-line (i.e., compared with the richest experience plus the easiest testing condition), main effects of all three other types of learning experience increased naming latencies, $t$ exposureonlyinSC\&testedinSC $(354.89)=3.05$, p $\quad<0.001, \quad \mathrm{t} \quad$ exposureonlyinSC\&testedinSH(indirectexposure) (380.26) $=1.73, p=0.09, \mathrm{t} \quad$ bi-dialectalexposure\&testedinSH(340.85) $=$ 2.83, $p<0.001$. However, with $\mathrm{SH}$ as dialect of operation, $\mathrm{SC}-\mathrm{SH}$ bi-dialectals' naming latencies were significantly reduced, $\quad t \quad S C-S H b i-$ dialectal : bi-dialectalexposure\&testedinSH (333.32) $=-4.16, \quad p \quad<0.001, \quad t$ SC-SHbi-dialectal : exposureonlyinSC\&testedinSH(indirectexposure) $(370.75)$

$=-2.04, p<0.05$, which reversed the interfering main effects. SC-OD bi-dialectals also enjoyed a facilitatory effect from bi-dialectal exposure when dialect of operation was $\mathrm{SH}$, $t_{S C-O D b i-d i a l e c t a l}:$ bi-dialectalexposure\&testedinSH $(340.77)=-2.07$, $p<0.05$.

Post-hoc lsmeans model estimates (Kuznetsova et al., 2013) in Figure 12 showed the importance of long-term and shortterm bi-dialectal experience in naming tasks. (1) Short-term bi-dialectal exposure reduced general SC naming latencies across all groups. However, (2) in the recipient dialect $\mathrm{SH}$, only bi-dialectals were significantly facilitated by bi-dialectal exposure. (3) SC monolectals responded slower in $\mathrm{SH}$ than in SC, but SC-SH bi-dialectals responded faster in $\mathrm{SH}$ than in SC.

\section{DISCUSSION}

This study investigated the cognitive processes underlying crossdialectal lexical borrowing in the auditory comprehension and production of bi-dialectals and monolectals. The following five findings shed light on individuals' collective cognitive processes involved in the initial stage of the social emergence of loanwords.

\section{Long-Term Bi-Dialectism Counteracts Age-Related Reduction of Word-Learning Ability}

The comprehension borrowing experiment showed that, whether the stimuli were presented in the source form or the loan form, the accuracy of word identification reduced with age in all three groups of participants, as predicted by the age-related gradual reduction hypothesis (Connor et al., 2006). However, the age-related reduction of bi-dialectals when it comes to lexicallearning ability is smaller and starts at a later age ( $>35$ years of age). This indicates that long-term bi-dialectism may have protective effects on both word learning and cross-dialectal comprehension borrowing of recently learned novel words.

\section{Short-Term Bi-Dialectal Exposure Facilitates Production Borrowing by Enriching Instead of Increasing Lexical Exposure}

In the production borrowing test, compared with creatively producing nonce loanwords (given source-dialect-only prior 


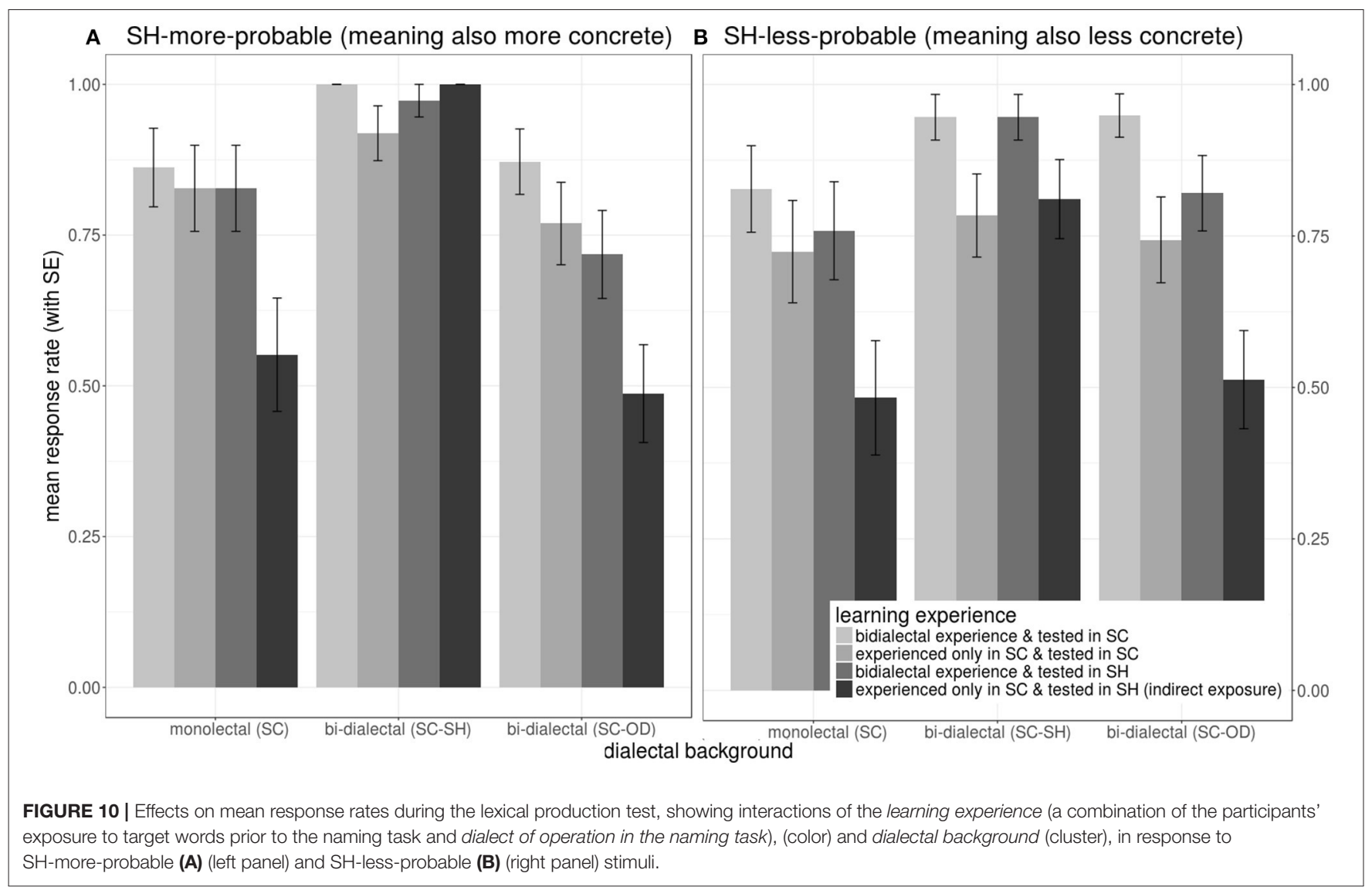

exposure), reproducing briefly established loanwords (with short-term bi-dialectal prior exposure) resulted in more responses and higher accuracies. Similarly, short-term bidialectal prior exposure also facilitates the production of source word forms. Since the duration of short-term dialectal-general exposure (direct and indirect together) to the target loanwords was held the same in the experiment, this finding suggested that it was enriched instead of increased prior lexical exposure that facilitated production borrowing. The finding is in line with previous research findings that increased lexical variability facilitates word learning (for e.g., see Lively et al., 1993). It also revealed that cross-dialectal comprehension borrowing has beneficial effects in consolidating lexical representations of recently learned novel words in both source and recipient dialects. This reciprocal cognitive benefit can explain the historical linguistic phenomenon that cross-dialectal borrowing seems to be very frequent in bi-dialectal communities with long-term co-evolving dialects (Trudgill, 1986).

\section{Bi-Dialectals Store New Lexical Items, While Monolectal Assimilate Lexical Variants}

As shown by the results of GAM analyses (Figures 6, 7), both groups of bi-dialectals responded more slowly or non-linearly to words with increased cross-dialectal similarity. These effects are in line with previous research findings of cross-linguistic lexical competition and parallel inhibition (for example, see Dijkstra et al., 2010; Wu et al., 2019) and revealed an early existence of lexical-level cross-dialectal competition as loan forms were initially introduced. In contrast, none of such lexicallevel effects was found in the monolectals. The facilitatory effects of monolectals of cross-dialectal similarity indicated that they probably performed perceptual assimilation (Best and Strange, 1992) and accent-adaptation (Sumner and Samuel, 2009; Larraza and Best, 2018) mechanisms instead when they encounter crossdialectal loan forms for the first time.

Note that bi-dialectals without prior recipient-dialectspecific experience showed similar response patterns as bi-dialectals who are speakers of the recipient dialect but differed significantly from source-dialect monolectals. This indicated that the difference in cross-dialectal lexical representation pattern during comprehension borrowing resulted from bi-dialectism in general instead of recipient-dialect-specific experience.

Hence, hearing cross-dialectal loan forms, monolectals tend to temporarily apply perceptual assimilation and accent adaptation mechanisms to process the new "accentual variants" and hence maintain a relatively stable state of the mental lexicon. On the other hand, bi-dialectals readily add new lexical items to their integrated mental lexicon and update their mental lexicons more actively. Zooming out from 


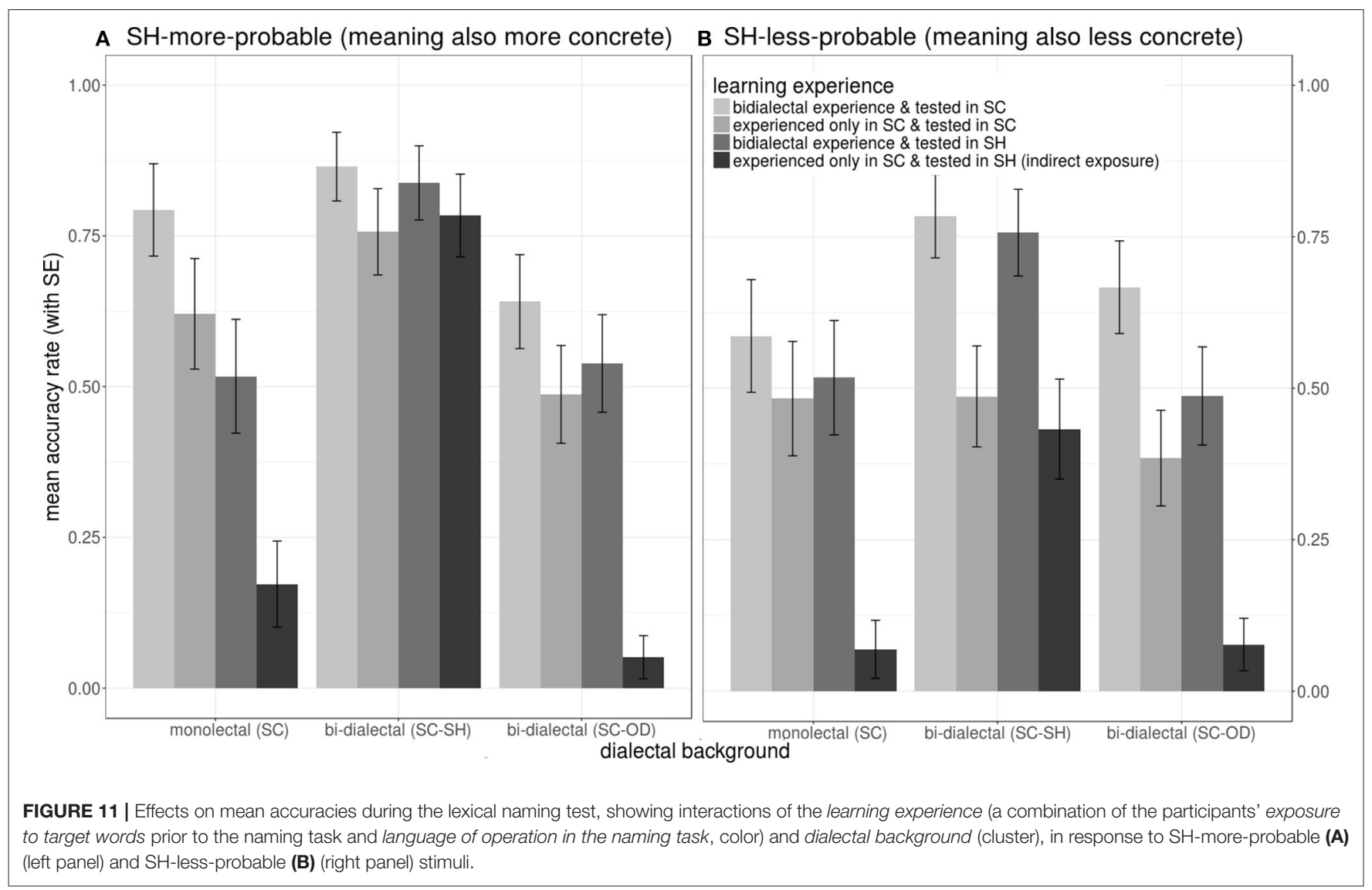

individual speakers to linguistic communities, one can further imagine that, with co-evolving dialects in context, a larger proportion of bi-dialectals may mean more active and sustainable cross-dialectal lexical borrowing at the community level (see also previously, Poplack et al., 1988 on highly bilingual communities), which may expedite lexical alignment between the two involved dialects (or languages) in linguistic evolution.

\section{Bi-Dialectals Borrow Compounds Based on Morphemes, While Monolectals Cast Transferred Forms Holistically}

Previously, it was found that constituent effects are less likely to surface in production than in comprehension (Janssen et al., 2014). However, the current study found recipient-dialectspecific morphological probability effects of bi-dialectals in both of the comprehension and production borrowing tests. In the comprehension borrowing, both groups of bi-dialectals showed different similarity effects for SH-more-probable vs. SH-lessprobable targets, both differing significantly from the faciliatory effect of monolectals of cross-dialectal similarity. These findings suggest that bi-dialectals, even when recognizing cross-dialectal loanwords in an unfamiliar dialect, tend to create lexical representations for the loanwords by re-encoding etymologically related morphemes between the two dialects, while monolectals do not re-encode compound constituents.
Evidence for the cross-dialectal morpheme-based recoding of bi-dialectals was also found in production borrowing. However, only the SC-SH bi-dialectals were more effective and efficient in creating $\mathrm{SH}$-more-probable nonce loanwords than in creating SH-less-probable loanwords. Thus, re-encoding of compound constituents in production borrowing should be attributed to recipient-dialect-specific experience. Unlike in comprehension borrowing, only bi-dialectals who speak the recipient dialect can make use of the ETE morphemes to produce loanwords.

Again, zooming out to the level of a linguistic community, one can imagine that a linguistic community with more bidialectals would have more cross-dialectal loanwords that are aligned at morphemic level with the source forms, whereas a linguistic community with more monolectals when in contact with another dialect would be biased toward cross-dialectal loanwords that are phonologically adapted with whole words as the unit of borrowing. This theory may also apply to longterm co-evolving languages given additional conditions (such as biliteracy, supposedly). For instance, since the late-nineteenthcentury, after the Japanese colonization of Korea, with the number of Korean-Chinese bilinguals decreasing significantly, the old morpheme-based Chinese loan words in Korean have been lost to a large degree, whereas more recent Chinese loan words in Korean are scarce and mostly holistically casted (Yu and Wu, 2021). 


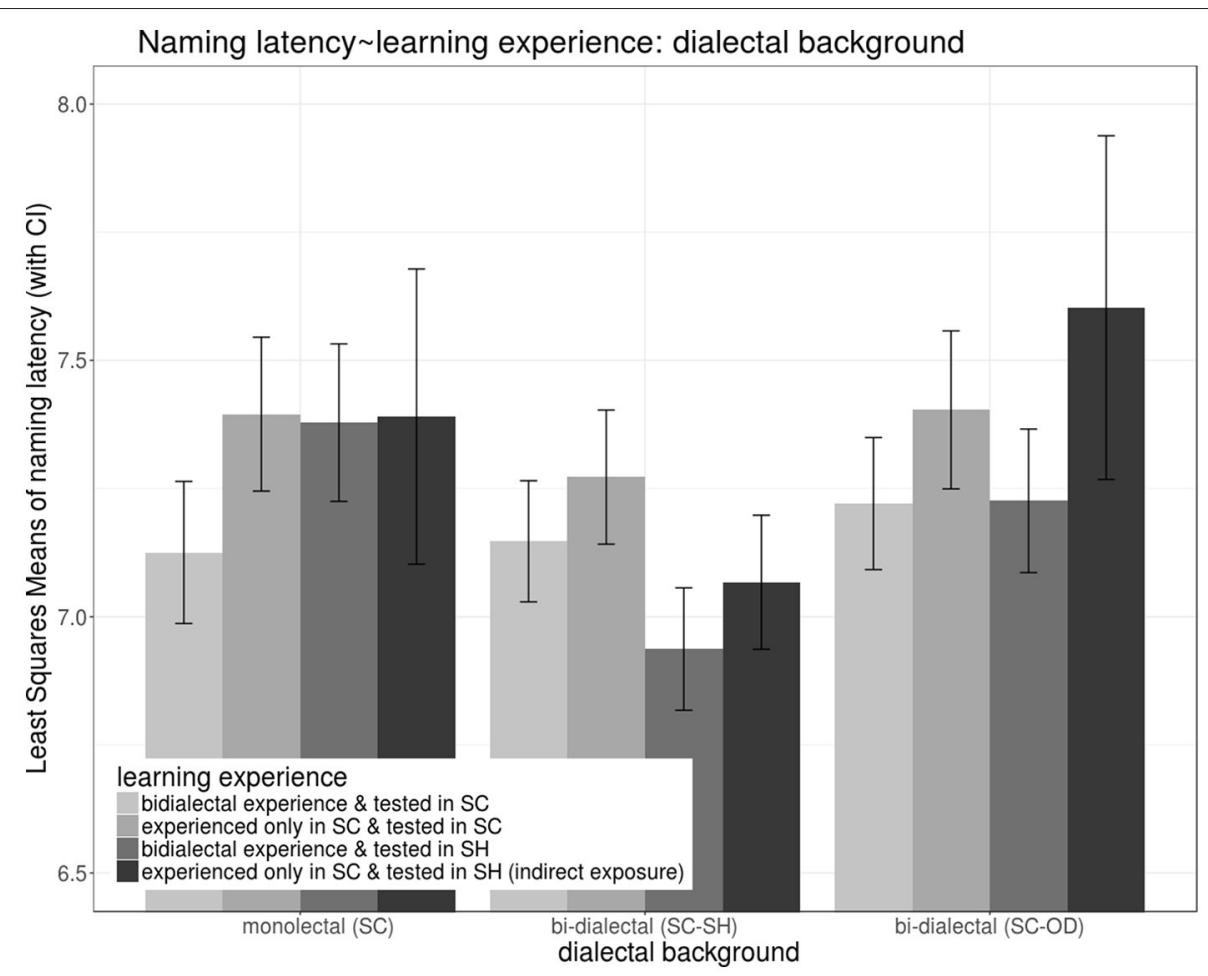

FIGURE 12 | Effects on naming latencies during the lexical production test, showing an interaction between learning experience (a combination of the participants' exposure to target words prior to the naming task and language of operation in the naming task, color) and dialectal background (cluster).

The findings presented in Short-Term Bi-Dialectal Exposure Facilitates Production Borrowing by Enriching Instead of Increasing Lexical Exposure and Bi-Dialectals Store New Lexical Items, while Monolectal Assimilate Lexical Variants sections suggested that language ecology (social bi-dialectism vs. social monolectism), which is important for the evolution of loanwords and dialects in contact, takes effect with deeprooted cognitive motives. It has been commonly known by contact linguists that the introduction of loan forms begins with multiple alternative forms but only one or two forms would finally be established in the linguistic community (for examples, see Weinreich, 1953; You, 2016). Our findings suggested that the competing loan forms may emerge from different cognitive routes of lexical borrowing, in that bidialectals favor compound borrowing based on morphemes, which focuses on the morpheme-level of units as the target of borrowing, while monolectals favor assimilating holistically casted transferred forms, which focuses on the whole-wordlevel of units as lexical variants of existing native words. We could further infer that the proportions and relative social statuses of bi-dialectals vs. monolectals in the linguistic community may influence the fate of candidate loan forms, wherein a demographically dominant group of speakers may lead the trend by using loan forms that fit their favored route of borrowing. While the collectively favored loan forms got quickly established and turn into social conventions, the alternative forms became obsolete. This inference in real-world language communities may be further implicated in agent-based computational simulation.

\section{Dialectal Backgrounds Influence Inference but Not Conflict Resolution in Comprehension Borrowing}

The comprehension borrowing experiment showed that lowcompetition context facilitates lexical identification. However, dialectal backgrounds showed no interaction with the high- and low-competition contexts. Thus, bi-dialectals did not show any advantage in conflict resolution in this cross-dialectal lexical borrowing experiment.

However, regarding the noise trials, SC-OD bi-dialectals were less likely to use inference to figure out the association of the image and the auditory input. Since such inference was not mandatory in the experiment, this difference may be due to the selective lack of adherence of these bi-dialectals to the mutual exclusivity principle (Markman, 1992) under the cognitive pressure from the context of an unfamiliar dialect. It is known that even monolingual children can accept the violation of MEP as it happens across languages (Frank and Poulin-Dubois, 2002), which may be a similar situation as the SC-OD bi-dialectals encountered in this task.

Our findings and these language-development data taken together suggested that monolingualism or monolectism may not be the default setting of language evolution. Whether 
adults or children, monolinguals, or bilinguals, we are always ready to neglect the mutual exclusivity principle as long as the two-to-one form-meaning association appears across linguistic varieties. This finding suggested that lexical development in highly bilingual communities and the corresponding language co-evolution may be grounded on a different cognitive basis other than mutual exclusivity.

In sum, this study tested the roles of long-term (age, bi-dialectism, and recipient-language-specific experience) and short-term (bi-dialectal lexical exposure and targetspecific exposure) linguistic experience in comprehension and production borrowing. The results showed that bi-dialectism provides a general protective influence against age-related deterioration of word learning and cross-dialectal lexical borrowing abilities. Bi-dialectal exposure takes effect not only by increasing the amount of lexical exposure, but more importantly by enriching the experience of bi-dialectals with target new words and helping them encode and decode words more deeply. The long-term bi-dialectal experience of individuals, as well as their short-term exposure to each specific loanword, may collectively shape the route of lexical evolution of co-evolving linguistic varieties.

\section{DATA AVAILABILITY STATEMENT}

The datasets presented in this study can be found in online repositories. The names of the repository/repositories and accession number(s) can be found below: The datasets Cross-Dialectal Novel Word Learning and Borrowing for this study can be found in the Open Science Framework https://osf. io/p9yw4/.

\section{ETHICS STATEMENT}

The studies involving human participants were reviewed and approved by the IRB Commitee of East China Normal University. The patients/participants

\section{REFERENCES}

Aktürk-Drake, M. (2014). The role of perceptual salience in bilingual speakers' integration of illicit long segments in loanwords. Lingua 143, 162-186. doi: 10.1016/j.lingua.2014.02.006

Antoniou, M., Tyler, M. D., and Best, C. T. (2012). Two ways to listen: do L2dominant bilinguals perceive stop voicing according to language mode? J. Phon. 40, 582-594. doi: 10.1016/j.wocn.2012.05.005

Barcroft, J., and Sunderman, G. (2008). Learning new words for objects and nonobjects: Theoretical and methodological implications. Ment. Lex. 3, 325-348. doi: 10.1075/ml.3.3.05bar

Bates, D., Maechler, M., Bolker, B., and Walker, S. (2013). Ime4: Linear MixedEffects Models Using Eigen and S4. R package version 1.0-4.

Best, C. T., and Strange, W. (1992). Effects of phonological and phonetic factors on cross-language perception of approximants. J. Phon. 20, 305-330. doi: 10.1016/S0095-4470(19)30637-0

Bialystok, E. (2009). Bilingualism: The good, the bad, and the indifferent. Biling. Lang. Cogn. 12, 3-11. doi: 10.1017/S13667289080 03477 provided their written informed consent to participate in this study.

\section{AUTHOR CONTRIBUTIONS}

JW designed and carried out the experiment, analyzed the data, and drafted the manuscript. WZ suggested several critical points regarding the theoretical background and implications in language evolution. $\mathrm{MH}$ suggested the theoretical implication of MEP. NOS revised the manuscript multiple times and improved the logical flow, layout, and phrasing in detail. All authors contributed to the article and approved the submitted version.

\section{FUNDING}

This work was supported by Chinese Fundamental Research Funds for the Central Universities (2017ECNU-YYJ017), by Shanghai Philosophy and Social Sciences Fund (2017BYY001), and by National Social Science Fund Major Projects (18ZDA296).

\section{ACKNOWLEDGMENTS}

We would like to thank the research assistants of LCE Lab, Jie Chen, Zhexuan Zhang, Wei Chen, Yiqi Zheng, and Juanyuan Zhao, for their meticulous efforts in recruiting suitable participants, our young SH informers Jingjing Miao, Juanyuan Zhao, Sichi Meng, Zhenghui Gong, Yibei Mu, Jiayi Jin, and Yewei Sun for their time and insights, as well as all the participants of different ages who traveled across the city to participate in the experiment.

\section{SUPPLEMENTARY MATERIAL}

The Supplementary Material for this article can be found online at: https://www.frontiersin.org/articles/10.3389/fpsyg. 2021.734527/full\#supplementary-material

Boersma, P. (2002). Praat, a system for doing phonetics by computer. Glot Int. 5, 341-345.

Cardimona, K., Smith, P., and Roberts, L. S. (2016). Lexical organization in second language acquisition: does the critical period matter? TESOL J. 7, 540-565. doi: $10.1002 /$ tesj.219

Chen, Y., and Gussenhoven, C. (2015). Shanghai Chinese. J. Int. Phon. Assoc. 45, 321-337. doi: 10.1017/S00251003150 00043

Connor, C. M., Craig, H. K., Raudenbush, S. W., Heavner, K., and Zwolan, T. A. (2006). The age at which young deaf children receive cochlear implants and their vocabulary and speech-production growth: is there an added value for early implantation? Ear Hear. 27, 628-644. doi: 10.1097/01.aud.0000240640.59205.42

Davidson, D., and Tell, D. (2005). Monolingual and bilingual children's use of mutual exclusivity in the naming of whole objects. J. Exp. Child Psychol. 92, 25-45. doi: 10.1016/j.jecp.2005.03.007

De Leeuw, E., and Celata, C. (2019). Plasticity of native phonetic and phonological domains in the context of bilingualism. J. Phon. 75, 88-93. doi: 10.1016/j.wocn.2019.05.003 
Dijkstra, T., Miwa, K., Brummelhuis, B., Sappelli, M., and Baayen, H. (2010). How cross-language similarity and task demands affect cognate recognition. J. Mem. Lang. 62, 284-301. doi: 10.1016/j.jml.2009.12.003

Dixon, R. M. W. (1997). The Rise and Fall of Languages. Cambridge: Cambridge University Press. doi: 10.1017/CBO9780511612060

Duanmu, S. (1999). Metrical structure and tone: evidence from Mandarin and Shanghai. J. East Asian Ling. 8, 1-38. doi: 10.1023/A:10083530 28173

Ernestus, M., and Baayen, R. H. (2003). Predicting the unpredictable: interpreting neutralized segments in Dutch. Language 79, 5-38. doi: 10.1353/lan.2003.0076

Erten, I. H., and Tekin, M. (2008). Effects on vocabulary acquisition of presenting new words in semantic sets versus semantically unrelated sets. System 36, 407-422. doi: 10.1016/j.system.2008.02.005

Ferguson, C. A. (1959). Diglossia. WORD 15, 325-340. doi: 10.1080/00437956.1959.11659702

Finkbeiner, M., and Nicol, J. (2003). Semantic category effects in second language word learning. Appl. Psycholinguist. 24, 369-383. doi: $10.1017 /$ S0142716403000195

Fitch, W. T. (2007). Linguistics: An invisible hand. Nature 449:665. doi: $10.1038 / 449665 a$

Forster, K. I. (1985). Lexical acquisition and the modular lexicon. Lang. Cogn. Process. 1, 87-108. doi: 10.1080/01690968508402073

Frank, I., and Poulin-Dubois, D. (2002). Young monolingual and bilingual children's responses to violation of the Mutual Exclusivity Principle. Int. J. Biling. 6, 125-146. doi: 10.1177/13670069020060020201

Gaskell, M. G., and Dumay, N. (2003). Lexical competition and the acquisition of novel words. Cognition 89, 105-132. doi: 10.1016/S0010-0277(03)00070-2

Giles, H., Taylor, D. M., and Bourhis, R. (1973). Towards a theory of interpersonal accommodation through language: some Canadian data. Lang. Soc. 2, 177-192. doi: $10.1017 /$ S0047404500000701

Grzega, J. (2003). Borrowing as a word-finding process in cognitive historical onomasiology. Onomasiol. Online 4, 22-42.

Haugen, E. (1950). The analysis of linguistic borrowing. Language 26:210. doi: $10.2307 / 410058$

Janssen, N., Pajtas, P. E., and Caramazza, A. (2014). Task influences on the production and comprehension of compound words. Memory Cogn. 42, 780-793. doi: 10.3758/s13421-014-0396-Z

Ji, X. (1948). Budda (浮屠) an Budda (佛) [浮屠与佛]. Acad. Sin. Bull. Natl. Res. Inst. Hist. Philol. (历史语言研究所集刊) 20, 95-105.

Jiang, N., and Forster, K. I. (2001). Cross-language priming asymmetries in lexical decision and episodic recognition. J. Mem. Lang. 44, 32-51. doi: 10.1006/jmla.2000.2737

Kaczer, L., Bavassi, L., Petroni, A., Fernández, R. S., Laurino, J., Degiorgi, S., et al. (2018). Contrasting dynamics of memory consolidation for novel word forms and meanings revealed by behavioral and neurophysiological markers. Neuropsychologia 117, 472-482. doi: 10.1016/j.neuropsychologia.2018. 07.001

Kaczer, L., Timmer, K., Bavassi, L., and Schiller, N. O. (2015). Distinct morphological processing of recently learned compound words: an ERP study. Brain Res. 1629, 309-317. doi: 10.1016/j.brainres.2015.10.029

Kalashnikova, M., Mattock, K., and Monaghan, P. (2015). The effects of linguistic experience on the flexible use of mutual exclusivity in word learning. Biling. Lang. Cogn. 18, 626-638. doi: 10.1017/S1366728914000364

Kang, Y. (2010). The emergence of phonological adaptation from phonetic adaptation: English loanwords in Korean. Phonology 27, 225-253. doi: 10.1017/S0952675710000114

Kaushanskaya, M., Yoo, J., and Van Hecke, S. (2013). Word learning in adults with second-language experience: effects of phonological and referent familiarity. J. Speech Lang. Hear. Res. 56, 667-678. doi: 10.1044/1092-4388(2012/11-0084)

Keuleers, E., Sandra, D., Daelemans, W., Gillis, S., Durieux, G., and Martens, E. (2007). Dutch plural inflection: the exception that proves the analogy. Cogn. Psychol. 54, 283-318. doi: 10.1016/j.cogpsych.2006.07.002

Kriengwatana, B., Escudero, P., and ten Cate, C. (2014). Revisiting vocal perception in non-human animals: a review of vowel discrimination, speaker voice recognition, and speaker normalization. Front. Psychol. 5:1543. doi: 10.3389/fpsyg.2014.01543

Kuznetsova, A., Brockhoff, P. B., and Christensen, R. H. B. (2013). lmerTest: tests for random and fixed effects for linear mixed effect models (lmer objects of lme4 package). R package version, 2-0.
Larraza, S., and Best, C. T. (2018). Differences in phonetic-to-lexical perceptual mapping of L1 and L2 regional accents. Biling. Lang. Cogn. 21, 805-825. doi: $10.1017 /$ S1366728917000323

Lederberg, A. R., and Spencer, P. E. (2005). "Critical periods in the acquisition of lexical skills: Evidence from deaf individuals," in Trends in Language Acquisition Research, eds. P. Fletcher and J. F. Miller (Amsterdam: John Benjamins Publishing Company), 121-145. doi: 10.1075/tilar.4.08led

Lenneberg, E. H., Chomsky, N., and Marx, O. (1967). Biological Foundations of Language. New York, NY: Wiley. doi: 10.1080/21548331.1967.11707799

Li, F., and $\mathrm{Xu}, \mathrm{X}$. (2021). Electrophysiological evidence for the coexistence of expectancy fulfillment and semantic integration during the processing of binding and compound nouns. Int. J. Psychophysiol. 166, 25-37. doi: 10.1016/j.ijpsycho.2021.05.004

Lindsay, S., and Gaskell, M. G. (2013). Lexical integration of novel words without sleep. J. Exp. Psychol. Learn. Memory Cogn. 39, 608-622. doi: 10.1037/a00 29243

Lively, S. E., Logan, J. S., and Pisoni, D. B. (1993). Training Japanese listeners to identify English/r/and/l/. II: the role of phonetic environment and talker variability in learning new perceptual categories. J. Acoust. Soc. Am. 94:1242. doi: 10.1121/1.408177

Mackey, W. F. (1970). "Interference, integration and the synchronic fallacy," in Georgetown University Round Table on Languages and Linguistics (Washington, D.C.: Georgetown University Press), 195-227.

Marian, V., Blumenfeld, H. K., and Boukrina, O. V. (2008). Sensitivity to phonological similarity within and across languages. J. Psycholinguist. Res. 37, 141-170. doi: 10.1007/s10936-007-9064-9

Markman, E. M. (1992). "Constraints on word learning: Speculations about their nature, origins, and domain specificity," in Modularity and Constraints in Language and Cognition: The Minnesota symposia on child psychology (Mahwah: Lawrence Erlbaum Associates), 59-101.

Mestres-Missé, A., Càmara, E., Rodriguez-Fornells, A., Rotte, M., and Münte, T. F. (2008). Functional neuroanatomy of meaning acquisition from context. J. Cogn. Neurosci. 20, 2153-2166. doi: 10.1162/jocn.2008.20150

Mulder, K., Dijkstra, T., and Baayen, H. (2015). Cross-language activation of morphological relatives in cognates: The role of orthographic overlap and task-related processing. Front. Human Neurosci. 9:16. doi: 10.3389/fnhum.2015.00016

Newport, E. L., Bavelier, D., and Neville, H. J. (2001). "Critical thinking about critical periods: Perspectives on a critical period for language acquisition," in Language,Brain, and Cognitive Development, ed. E. Dupoux (Cambridge, Massachusetts: The MIT Press), 482-502.

Pacilly, J. J. A. (2010). MarkIntervals.praat [Computer program] (accessed 24 Jan, 2010).

Peperkamp, S., Vendelin, I., and Nakamura, K. (2008). On the perceptual origin of loanword adaptations: experimental evidence from Japanese. Phonology 25, 129-164. doi: 10.1017/S0952675708001425

Poplack, S., and Sankoff, D. (1984). Borrowing: the synchrony of integration. Linguistics 22, 99-135. doi: 10.1515/ling.1984.22.1.99

Poplack, S., Sankoff, D., and Miller, C. (1988). The social correlates and linguistic processes of lexical borrowing and assimilation. Linguistics 26, 47-104. doi: 10.1515/ling.1988.26.1.47

Qiao, X., and Forster, K. I. (2013). Novel word lexicalization and the prime lexicality effect. J. Exp. Psychol. Learn. Memory Cogn. 39, 1064-1074. doi: $10.1037 / \mathrm{a} 0030528$

Qiao, X., and Forster, K. I. (2017). Is the L2 lexicon different from the L1 lexicon? Evidence from novel word lexicalization. Cognition 158, 147-152. doi: 10.1016/j.cognition.2016.10.026

R Core Team (2019). R: A Language and Environment for Statistical Computing [Computer program]. R Foundation for Statistical Computing, Vienna, Austria, version 3.6.2.

Reh, R. K., Hensch, T. K., and Werker, J. F. (2021). Distributional learning of speech sound categories is gated by sensitive periods. Cognition 213:104653. doi: 10.1016/j.cognition.2021.104653

Sabourin, L., Brien, C., and Burkholder, M. (2014). The effect of age of L2 acquisition on the organization of the bilingual lexicon: Evidence from masked priming. Bilingualism: Language and Cognition 17, 542-555. doi: $10.1017 /$ S1366728913000643

Sakamoto, Y., and Ishiguro, M. (1986). Akaike Information Criterion Statistics. Dordecht: Reidel Publishing Company. 
Sumner, M., and Samuel, A. G. (2009). The effect of experience on the perception and representation of dialect variants. J. Mem. Lang. 60, 487-501. doi: 10.1016/j.jml.2009.01.001

Swerts, M., Van Heteren, A., Nieuwdorp, C., Von Oerthel, E., and Kloots, H. (2021). Asymmetric forms of linguistic adaptation in interactions between Flemish and Dutch speakers. Front. Commun. 6:716444. doi: $10.3389 /$ fcomm.2021.716444

Tang, C., and Van Heuven, V. J. (2009). Mutual intelligibility of Chinese dialects experimentally tested. Lingua 119, 709-732. doi: 10.1016/j.lingua.2008.10.001

Thomason, S. G., and Kaufman, T. (1991). Language Contact, Creolization, and Genetic Linguistics. Berkeley: University of California Press.

Tinkham, T. (1997). The effects of semantic and thematic clustering on the learning of second language vocabulary. Second Lang. Res. 13, 138-163. doi: 10.1191/0267658976723 76469

Trudgill, P. (1986). Dialects in Contact. Oxford, UK; New York, NY, USA: B. Blackwell.

Van Rij, J., Wieling, M., Baayen, R. H., and van Rijn, H. (2015). itsadug: Interpreting Time Series, Autocorrelated Data Using GAMMs. [Computer program]. Available online at: https://cran.r-project.org/web/packages/itsadug.

Wang, F., and Wang, W. S.-Y. (2004). "Basic Words and Language Evolution (基本詞彙與語言演變), in Language and Linguistics (历史语言研究所集刊). $5,643-662$.

Wang, H. (2005). "Mismatch of Literary and Colloquial Strata and the Reconstruction of Strata (文白杂配与析层拟测), ” in Xiamen: The 38th SinoTibetan Linguistic Simposium (第 38 届国际汉藏语学术研讨会).

Wang, H., and Van Heuven, V. J. (2015). The interlanguage speech intelligibility benefit as bias toward native-language phonology. i-Perception 6:2041669515613661. doi: $10.1177 / 20416695156$ 13661

Wang, W. S.-Y., and Lien, C. (1993). "Bidirectional diffusion in sound change," in Historical Linguistics: Problems and Perspectives (London, New York: Longman), 345-400.

Weinreich, U. (1953). Languages in Contact: Finding and Problems. The Hague: Mouton.

Werker, J. F., and Hensch, T. K. (2015). Critical periods in speech perception: new directions. Annu. Rev. Psychol. 66, 173-196. doi: 10.1146/annurev-psych-010814-015104

Wig, N., and García-Sierra, A. (2021). Matching the mismatch: the interaction between perceptual and conceptual cues in bilinguals' speech perception. Bilingualism 24, 467-480. doi: 10.1017/S1366728920000553

Witzel, N. O., and Forster, K. I. (2012). How L2 words are stored: the episodic L2 hypothesis. J. Exp. Psychol. Learn. Memory Cogn. 38, 1608-1621. doi: $10.1037 / \mathrm{a} 0028072$

Wood, S. N. (2006). Generalized Additive Models: an Introduction with R. Florida: CRC Press. doi: 10.1201/97814200 10404

Wood, S. N. (2011). Fast stable restricted maximum likelihood and marginal likelihood estimation of semiparametric generalized linear models. J. R. Stat.
Soc. Ser. $B$ (Stat. Methodol.) 73, 3-36. doi: 10.1111/j.1467-9868.2010.0 0749.x

Wu, J. (2015). Tonal Bilingualism: The Case of Two Closely Related Chinese Dialects. Utrecht: LOT.

Wu, J., Chen, Y., Van Heuven, V. J., and Schiller, N. O. (2017). Interlingual two-to-one mapping of tonal categories. Biling. Lang. Cogn. 20, 813-833. doi: $10.1017 /$ S1366728916000493

Wu, J., Chen, Y., Van Heuven, V. J., and Schiller, N. O. (2019). Dynamic effect of tonal similarity in bilingual auditory lexical processing. Lang. Cogn. Neurosci. 34, 580-598. doi: 10.1080/23273798.2018.1550206

Xian, M. (2012). "Mismatch of literary and colloquial strata and historical strata in the related morphemes between Chinese and Vietnamese(语-越南语关系语素中的文白杂配与历史层次), ” in International Conference in Evolutionary Linguistics 2012 (Beijing), 1.

Yang, X. (1982). A Study on Literary and Colloquial Reading Systems in Southern Min Dialect(闽南语文白异读系统的研究)Dr. dissertation). Institute of Chinese Studies, Taiwan University, Taipei.

You, R. (2000). Chinese Dialectology (汉语方言学导论). Shanghai: Shanghai Educational Publishing House.

You, R. (2016). "Words of Foreign Origin in the 'Shanghai Tongsuyu Ji Yangjingbang'(《上海通俗语及洋泾浜》所见外来词研究), in Dialect contact treatise (方言接触论稿) (Shanghai: Fudan University Press), 153-180.

You, R. ed. (2013). A Linguistic Survey of Shanghai Dialects (上海地区方言调查研究). 1st ed. Shanghai: Fudan University Press.

$\mathrm{Yu}$, J.-H., and $\mathrm{Wu}$, J. (2021). A study of Korean-Chinese Contact Based on Korean Chinese-Source Words(基于韩语汉源词的韩汉词汇接触研究). [dissertation/master's thesis]. [Shanghai]: East China Normal University.

Zhang, J., and Meng, Y. (2016). Structure-dependent tone sandhi in real and nonce disyllables in Shanghai Wu. J. Phon. 54, 169-201. doi: 10.1016/j.wocn.2015.10.004

Conflict of Interest: The authors declare that the research was conducted in the absence of any commercial or financial relationships that could be construed as a potential conflict of interest.

Publisher's Note: All claims expressed in this article are solely those of the authors and do not necessarily represent those of their affiliated organizations, or those of the publisher, the editors and the reviewers. Any product that may be evaluated in this article, or claim that may be made by its manufacturer, is not guaranteed or endorsed by the publisher.

Copyright (c) 2021 Wu, Zheng, Han and Schiller. This is an open-access article distributed under the terms of the Creative Commons Attribution License (CC BY). The use, distribution or reproduction in other forums is permitted, provided the original author(s) and the copyright owner(s) are credited and that the original publication in this journal is cited, in accordance with accepted academic practice. No use, distribution or reproduction is permitted which does not comply with these terms. 